\title{
Hydro-mechanical behaviour of bentonite pellet mixtures
}

\author{
C. Hoffmann, E.E. Alonso *, E. Romero \\ Dept. of Geotechnical Engineering and Geosciences, Universitat Politècnica de Catalunya, cl Jordi Girona 1-3, 08034 Barcelona, Spain
}

Received 25 April 2005; received in revised form 11 April 2006; accepted 26 April 2006

Available online 23 October 2006

\begin{abstract}
Granular mixtures made of high-density pellets of bentonite are being evaluated as an alternative buffer material for waste isolation. Ease of handling is an often-mentioned advantage. The paper described the experimental program performed to characterize the hydromechanical behaviour of compacted pellet's mixtures used in the engineered barrier (EB) experiment.

The material tested in the laboratory was based in the pellet's mixtures actually used for the emplacement of the EB in situ experiment. Grain size distribution was adjusted to a maximum pellet size compatible with the specimen's dimensions. Dry densities of statically compacted specimens varied in most of the cases in the range: $1.3-1.5 \mathrm{Mg} / \mathrm{m}^{3}$. Pellets had a very high dry density, close to $2 \mathrm{Mg} / \mathrm{m}^{3}$.

The outstanding characteristic of these mixtures is its discontinuous porosity. Pore sizes of the compacted pellets vary around $10 \mathrm{~nm}$. However the inter-pellet size of the pores is four to five orders of magnitude higher. This double porosity and the highly expansive nature of the pellets controlled all the hydraulic and mechanical properties of the mixture.

Tests performed include infiltration tests using different water injection rates and mechanisms of water transfer (in liquid and vapour phases), suction controlled oedometer tests and swelling pressure tests. The interpretation of some of the tests performed required backanalysis procedures using a hydro-mechanical (HM) computer code.

Material response was studied within the framework of the elastoplastic constitutive model proposed by Alonso et al. [Alonso, E.E., Gens, A., Josa, A., 1990. A constitutive model for partially saturated soils. Géotechnique 40 (3), 405-430] (Barcelona Basic Model, BBM). Parameters for the model were identified and also a set of hydraulic laws necessary to perform coupled HM analysis.
\end{abstract}

(C) 2006 Elsevier Ltd. All rights reserved.

Keywords: Bentonite; Laboratory tests; Laboratory equipment; Partial saturation; Suction; Granular mixture

\section{Introduction}

Within the framework of the engineered barrier (EB) project (AITEMIN, 2001), a bentonite based pelletized material has been considered as an alternative buffer material for the isolation of high-level radioactive waste. The aim of using bentonite-crushed pellets as filler material in the construction of engineering barriers, is to improve some aspects of the barrier emplacement operations and avoid some of the difficulties experienced in alternative concepts previously tested. As the bentonite pellet mixtures can be emplaced using pneumatic projection techniques, the back-

\footnotetext{
* Corresponding author. Fax: +34 934017251.

E-mail address: eduardo.alonso@upc.edu (E.E. Alonso).
}

filling operation becomes an easier and potentially robotized procedure. Using this granular material as filler, the gap between the host rock and the buffer usually found when working with full bentonite block barriers it also minimized (ENRESA, 2000).

The "EB" project integrates two main groups of experimental activities, a real scale test performed at the underground laboratory of Mont Terri (Switzerland), and a comprehensive laboratory experimental programme. The field experiment has also been simulated as reported by Alonso and Hoffmann (2005). Fig. 1 shows a cross section of the proposed disposal concept and a scheme of the different activities performed within the project.

The aim of this paper is to present the main results of the experimental programme performed to characterize the hydro-mechanical response of compacted pellet's mixtures. 


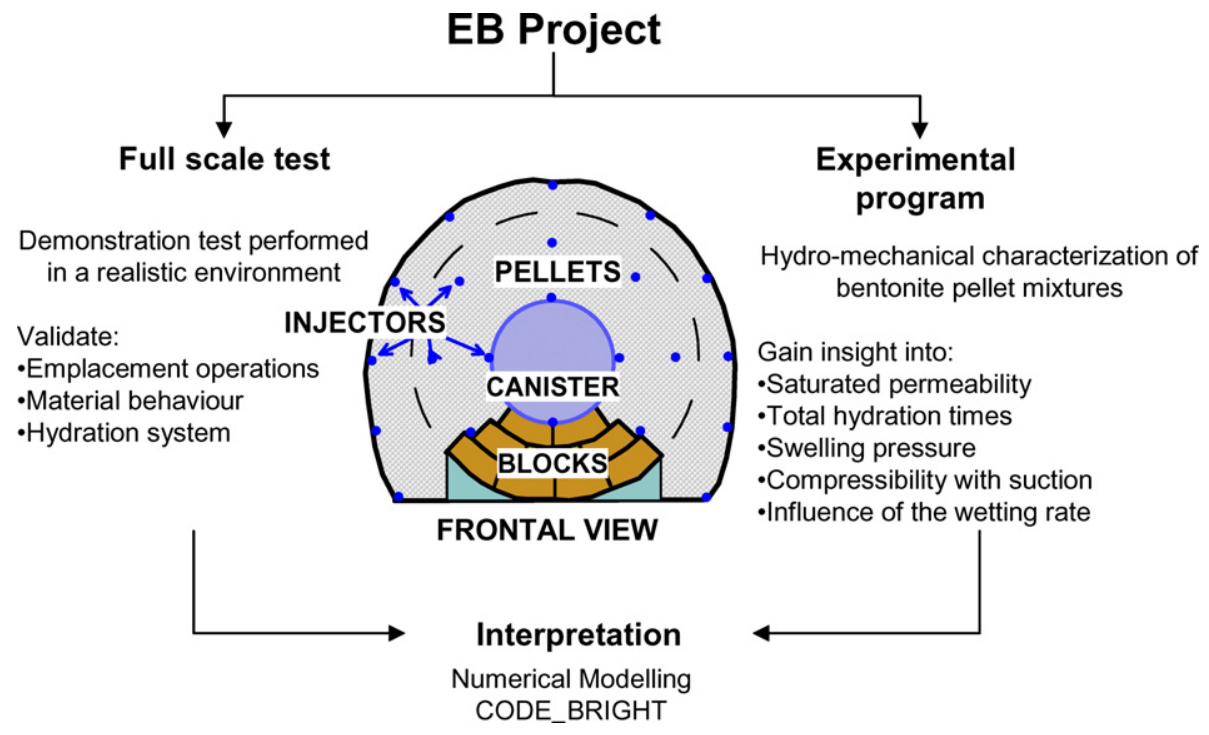

Fig. 1. EB Project. Scheme representing the different activities involved in the project. Cross section of the disposal tunnel, simulated tunnel and buffer.

A number of experimental issues for barrier performance were considered when the experimental program was defined: the expected saturation time of the barrier, the evolution of permeability, the water retention properties of the mixture, the effect of suction on mixture compressibility and the development of swelling pressure. Given the wide range of suctions involved from the initial dry state to the fully saturated situation, several suction control techniques have been handled. A good proportion of the tests reported were performed in special cells designed specially for the envisaged tests.

Due to the small amount of free water available in the host clay shale formation (Opalinus clay), an artificial hydration system was needed in order to saturate the buffer within reasonable testing times. The saturation process was forced by injecting liquid water into the buffer material by means of a system of interconnected tubes, Fig. 2. Tubes are connected in such a way that the water goes into the material from the front to the back of the small emplacement tunnel and from the floor to the roof.

The paper starts with a description of the pellet fabrication process, sample preparation procedures and the fabric characteristics of the bentonite pellet mixtures. Results on swelling pressure and saturated permeability are then given. The hydro-mechanical response of the material during the hydration process, is discussed on the basis of infiltration and suction controlled tests performed in special oedometer cells. Results are interpreted within the framework of a constitutive elastoplastic law, which seems to be well suited to describe the pellet's mixtures.
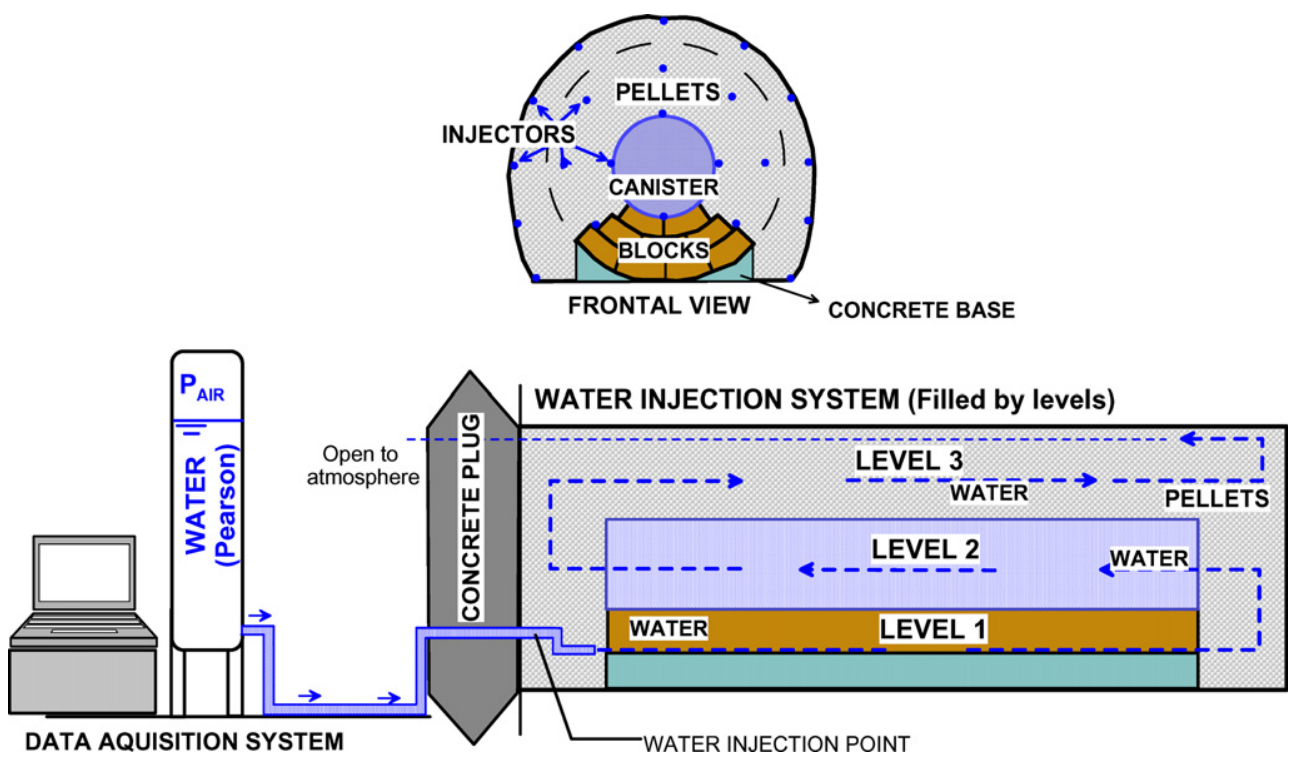

Fig. 2. Scheme of the artificial hydration system. 


\section{Tested material}

\subsection{FEBEX bentonite and pellet fabrication procedure}

Bentonite pellets were obtained from a $\mathrm{Ca}$-bentonite powder (FEBEX bentonite; ENRESA, 2000). Powder was preheated $\left(120^{\circ} \mathrm{C}\right)$ and then compacted using a roller press. As a result of this process, very high dry density granules with very low water content were obtained. This process is schematically represented in Fig. 3. The fraction of granules with sizes larger than $10 \mathrm{~mm}$ was used as the base material for the production of pellets using a jaw crusher. Basic properties of FEBEX bentonite and the initial compaction state of pellets is shown in Table 1 .

\subsection{Pellet mixtures and sample preparation}

The material tested in the laboratory was based on the pellet's mixtures actually used for the emplacement of the EB "in situ" experiment. Grain size distribution was adjusted to a maximum pellet size compatible with the specimen's dimensions. A minimum size of $0.4 \mathrm{~mm}$ was

\section{Bentonite pellet mixtures fabrication}

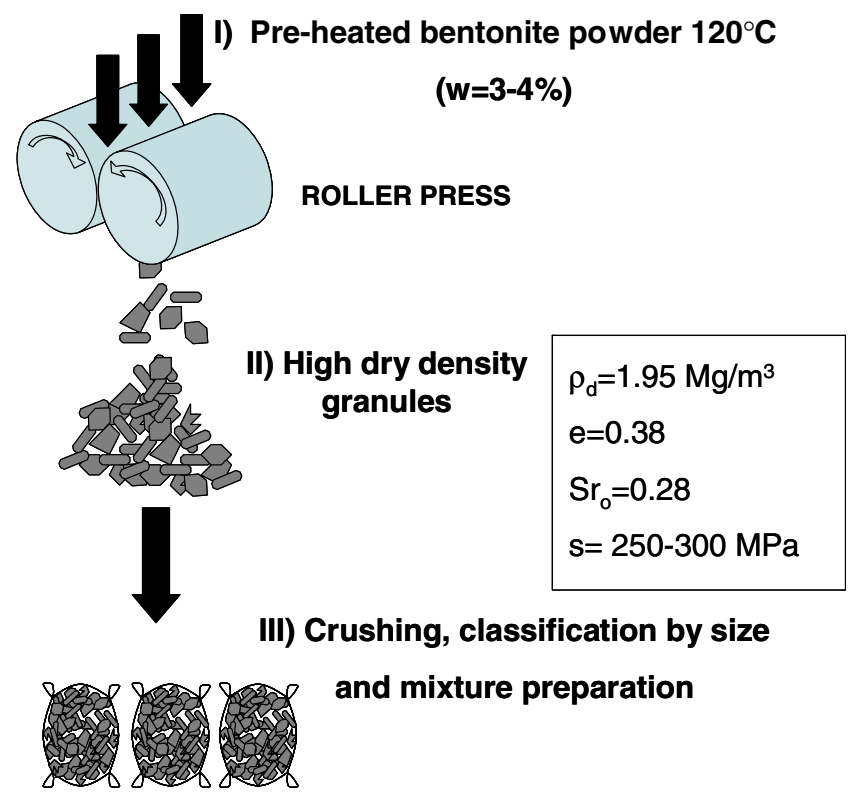

Fig. 3. Fabrication process of the bentonite pellets.

Table 1

Material properties: FEBEX bentonite powder and bentonite pellets

\begin{tabular}{llll}
\hline$\rho_{\mathrm{s}}\left(\mathrm{Mg} / \mathrm{m}^{3}\right)$ & $w_{\mathrm{P}}(\%)$ & $w_{\mathrm{L}}(\%)$ & $\%$ of particles $<75 \mu \mathrm{m}$ \\
\hline FEBEX Ca-bentonite & 47 & 93 & 85 \\
2.7 & $e_{0}$ & $w_{0}(\%)$ & Initial suction $(\mathrm{MPa})$ \\
$\rho_{\mathrm{d}}\left(\mathrm{Mg} / \mathrm{m}^{3}\right)$ & 0.38 & $3-4$ & $250-300$ \\
\hline Pellets & & & \\
1.95 & $\rho^{2}$ &
\end{tabular}

$\rho_{\mathrm{s}}$ : mineral density; $\rho_{\mathrm{d}}$ : dry density; $e_{0}$ : initial void ratio; $w_{0}$ : initial water content; $w_{\mathrm{L}}$ : liquid limit; $w_{\mathrm{P}}$ : plastic limit.
Grain size distribution of tested material

$$
p=\frac{\sqrt{D / D_{\max }}-\sqrt{D_{\min } / D_{\max }}}{1-\sqrt{D_{\min } / D_{\max }}}
$$

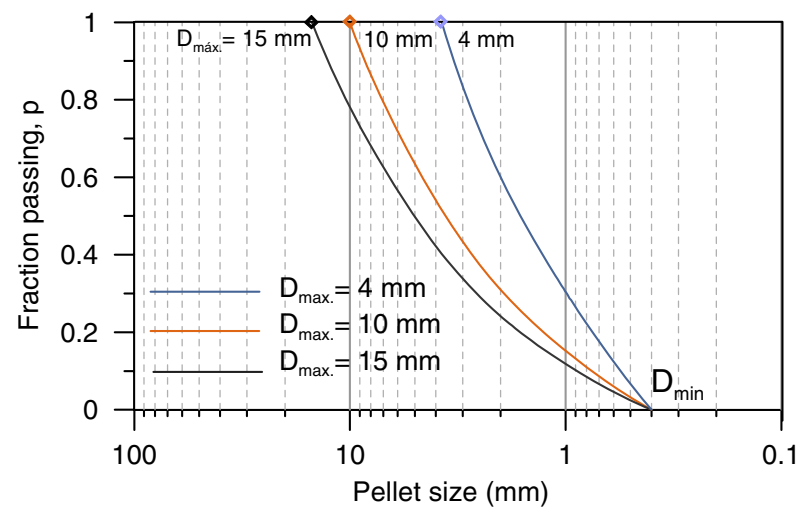

Fig. 4. Grain size distribution of the tested material.

selected in order to avoid segregation during sample preparation. Segregation of this fraction was observed in the preparation of samples using the gravity fall method in a Perspex wall cell $(70 \mathrm{~mm}$ in diameter and $15 \mathrm{~mm}$ high).

The maximum pellet size used for sample preparation was selected considering the sample size of the different testing cells. $D_{\max }=4 \mathrm{~mm}$ was used for test series performed on samples $50 \mathrm{~mm}$ in diameter and $20-\mathrm{mm}$ high. Values of $D_{\max }=10$ or $15 \mathrm{~mm}$ were used for tests performed on samples 50 or $75 \mathrm{~mm}$ in diameter and 50 or $100 \mathrm{~mm}$ high, respectively.

Grain size distribution curves are shown in Fig. 4. The curves shown are given by the following expression:

$p=\frac{\sqrt{D / D_{\max }}-\sqrt{D_{\min } / D_{\max }}}{1-\sqrt{D_{\min } / D_{\max }}}$

where $p$ represents the fraction passing referred to the total dry mass, $D$ is the granule size and $D_{\max }$ and $D_{\min }$ are the corresponding maximum and minimum pellet sizes.

A pluviation method for specimen preparation leads to very low dry densities $\left(1.05-1.15 \mathrm{Mg} / \mathrm{m}^{3}\right)$. Specimens have been tested at dry densities in the range $1.05-1.90 \mathrm{Mg} / \mathrm{m}^{3}$ and therefore they require in most cases some extra compaction. Specimens have been prepared by one-dimensional static compaction (rate of vertical displacement: $0.2 \mathrm{~mm} / \mathrm{min}$ ). The vertical stress required to reach a given dry density is shown in Fig. 5. In order to study the effect of the compaction process on pellet breakage, the grain size distributions before and after sample preparation were determined. Fig. 6 shows the effect of compaction to a dry density of $1.5 \mathrm{Mg} / \mathrm{m}^{3}$. A $10 \%$ increase in the finer fraction is measured.

\subsection{Pore size distribution}

Mercury intrusion porosimetry (MIP) tests were performed to characterize the multiple-porosity network of 


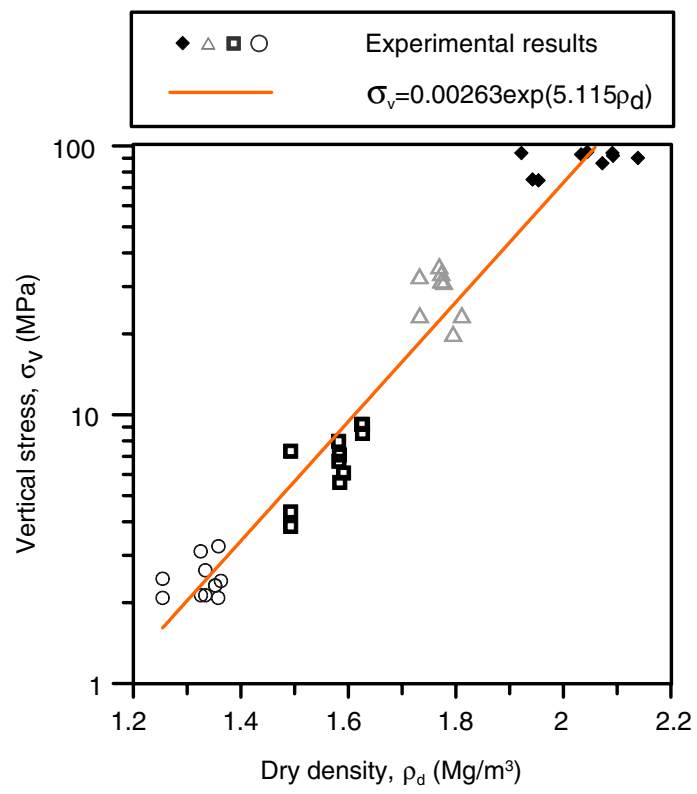

Fig. 5. Vertical stress necessary to obtained a desired dry density of the pellet's mixture.

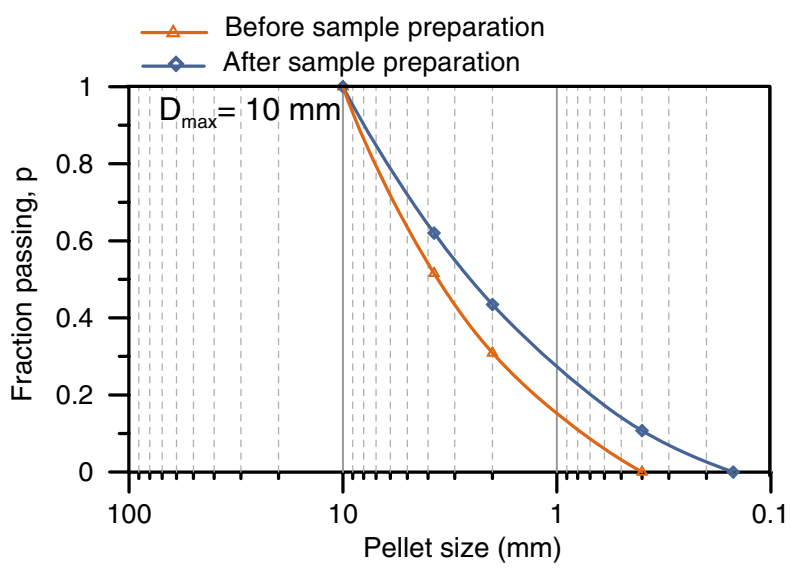

Fig. 6. Grain size distribution before and after sample compaction to a dry density of $1.5 \mathrm{Mg} / \mathrm{m}^{3}$.

the artificially prepared packing at different dry densities ranging from 1.2 to $1.95 \mathrm{Mg} / \mathrm{m}^{3}$.

Fig. 7a shows the measured pore size density function of a sample prepared using a gravity fall compaction procedure which results in a dry density value of $\rho_{\mathrm{d}}=1.15 \mathrm{Mg} / \mathrm{m}^{3}$. The sample was prepared using a uniform pellet fraction with sizes varying between 1 and $2 \mathrm{~mm}$ and was directly poured into the sample chamber of the MIP equipment. The pore size density function of this sample shows a three-mode curve with characteristic pore sizes of $13 \mathrm{~nm}, 3 \mu \mathrm{m}$ and $250 \mu \mathrm{m}$. The pore size distribution measured in a high-density pellet $\left(\rho_{\mathrm{d}}=1.95 \mathrm{Mg} / \mathrm{m}^{3}\right)$ is shown in Fig. 7b. Comparing both distributions, two types of pores can be identified. The first group of pores is associated with the inter-pellet voids and displays a characteristic size at around $250 \mu \mathrm{m}$. The second group of pores
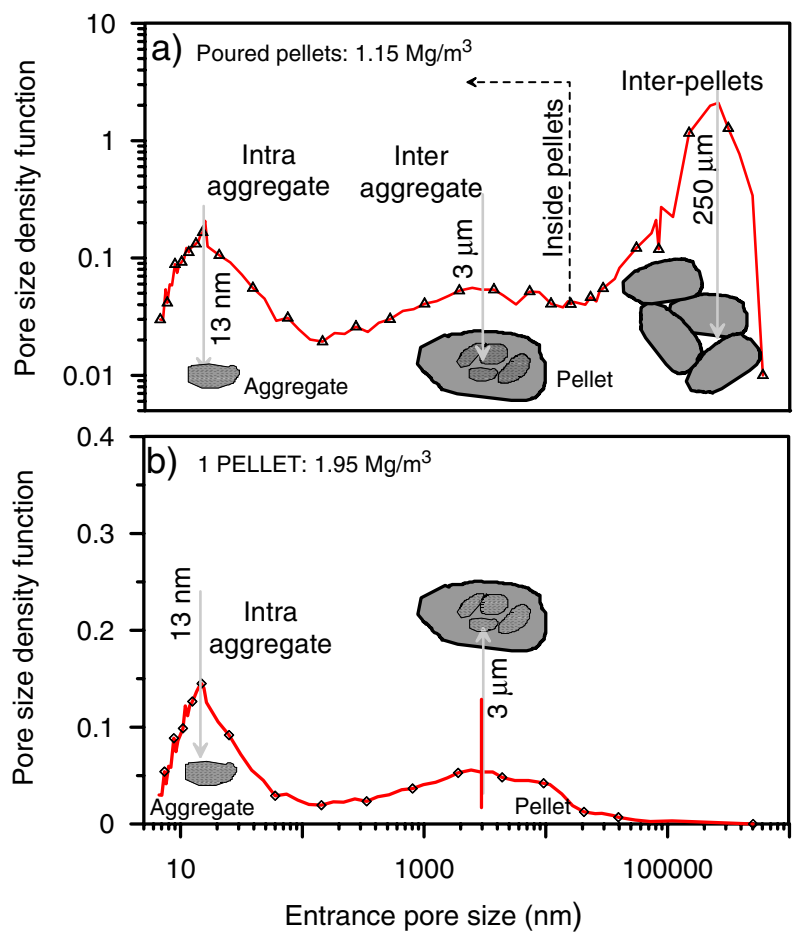

Fig. 7. Pores size distribution of the bentonite pellets. (a) Sampled poured into the sample holder. (b) High density granule.

corresponds to the intra-pellet voids and presents a bimodal distribution with characteristic sizes at $13 \mathrm{~nm}$ and $3 \mu \mathrm{m}$. These modes values are associated with the intraaggregate and inter-aggregate pores (pores inside and between the clay aggregates contained in a pellet).

Additional pore size distribution tests were performed on pellet samples prepared at different dry density values of $1.35,1.45$ and $1.7 \mathrm{Mg} / \mathrm{m}^{3}$. They are shown in Fig. 8. The three densities exhibit a bi-modal pore size distribution.

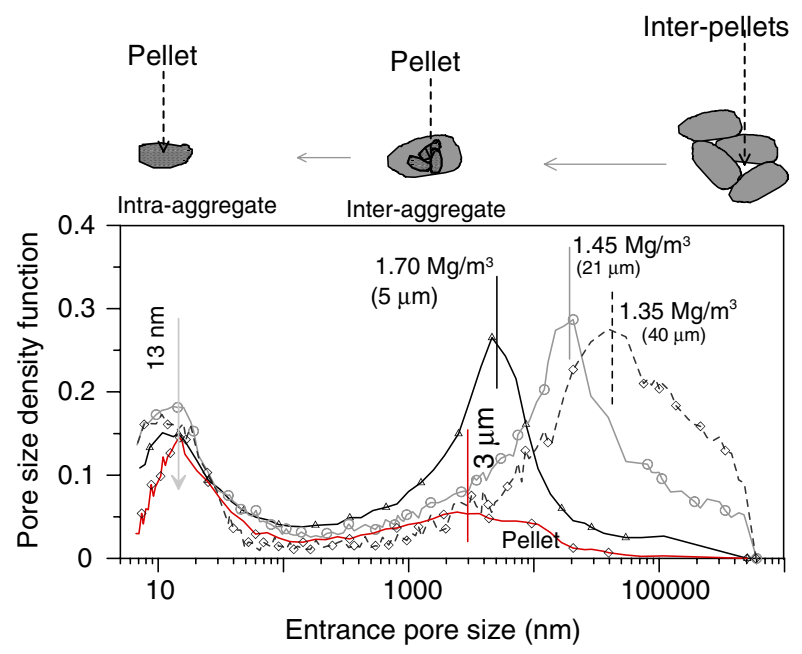

Fig. 8. Effect of degree of compaction on pore size distribution. Samples prepared using static compaction. Also shown are the results for a pellet. 
The group of small size pores is common to all dry densities and it corresponds to the pores inside the clay aggregates. The group of largest pores has a dominant size controlled by the level of specimen packing.

The set of results given indicates that the pore structure of a compacted specimen made of high-density pellets may be described as a superposition of pore networks with widely different sizes. The smaller group of pores (micropores) remains essentially constant as the compaction intensity changes. Changes in dry density result only in changes in the intra-pellet porosity (macropores).

The EB experiment does not involve heating of the buffer and therefore the effects of temperature on pellet aggregates are not covered in this paper. Pusch et al. (2003) reported that hot vapour with temperatures in excess of $110^{\circ} \mathrm{C}$ leads to a reduction of the swelling pressure of highly compacted pellets of MX-80 bentonite. They attributed the reduction of swelling potential to the formation of silica cements between clay lamellae. Under room temperatures, however, pellet mixtures and compacted blocks of Calcium FEBEX bentonite having the same dry density exhibited the same swelling pressure.

\section{Experimental programme}

In Performance Assessment exercises concerning the long term behaviour of waste repositories it is a usual assumption to consider fully saturated buffer. Process understanding requires, however, information on the transient wetting period. Some tests were designed to obtain basic properties (permeability, swelling pressure) for the fully hydrated material and for different initial states of the mixture (dry densities). The majority of tests performed addressed, however, the response during the wetting stage with or without suction control.

The average dry density of the emplaced material was about $1.36 \mathrm{Mg} / \mathrm{m}^{3}$ (NAGRA, 2003). Possible heterogeneities of the fill dry density and its range were inferred from previous emplacement trials performed in a one-to-one scale wooden tunnel, NAGRA (2003). In additional tests performed prior to the test emplacement, the average "drop" density of the fill was $1.46 \mathrm{Mg} / \mathrm{m}^{3}$, with maximum and minimum values of 1.52 and $1.28 \mathrm{Mg} / \mathrm{m}^{3}$ respectively (NAGRA, 2003). Given these results, most tests were performed on samples having dry density values ranging from 1.3 to $1.5 \mathrm{Mg} / \mathrm{m}^{3}$. Despite these results, there is a risk for large empty voids developing inside the buffer. The heterogeneous nature of the "in situ" fill was indirectly detected, during the wetting phase, by transient drops of the pressure measured in most of the stress cells installed. These drops indicated local collapse phenomena within the fill. However, all the stress cells recorded a systematic increase in swelling pressure, which consistently reached values close to $1 \mathrm{MPa}$ after two years of hydration. The entire buffer seemed to reach a reasonable confining stress. Further details are given in Alonso and Hoffmann (2005).

\subsection{Saturated mixtures}

\subsubsection{Permeability}

Saturated permeability was determined by means of constant head permeability tests performed on samples prepared at dry density values varying from 1.05 to $1.6 \mathrm{Mg} / \mathrm{m}^{3}$ (Fig. 9). Results obtained are in general agreement with the permeability values measured in samples prepared using compacted FEBEX bentonite specimens (ENRESA, 2000) which followed a different manufacturing procedure (in particular, they did not suffer any preheating to reduce the initial water content). The saturated permeability of the material is controlled by the dry density sample and can be described by the following regression:

$\ln \left(k_{\mathrm{w}}\right)=-9.73 * \rho_{\mathrm{d}}-13.79$

where $k_{\mathrm{w}}$ is the saturated permeability expressed in $\mathrm{m} / \mathrm{s}$ and $\rho_{\mathrm{d}}$ is the dry density of the sample in $\mathrm{Mg} / \mathrm{m}^{3}$.

\subsubsection{Swelling response}

The response of the material under different confining conditions was measured in two series of tests: Wetting under constant load and wetting at constant volume tests. Stress paths followed during both series of tests are plotted in a qualitative way in $\left(\sigma_{\mathrm{v}}, s\right)$ planes $\left(\sigma_{\mathrm{v}}\right.$ : total vertical stress; $s$ : specimen suction) in Figs. 10 and 12. A loading collapse (LC) yield locus (see Alonso et al., 1990) is also represented to mark the onset of irreversible deformations (collapse).

In the first group of tests, samples were first loaded, starting at compaction conditions (path 1-2 in Fig. 10) and then they were soaked at constant vertical stress (path $2-3$ in Fig. 10). Four series of tests were performed on samples prepared at dry density values of 1.3, 1.5, 1.7 and $1.9 \mathrm{Mg} / \mathrm{m}^{3}$ and different vertical stress levels were applied. Results obtained are presented in Fig. 11. A classical result

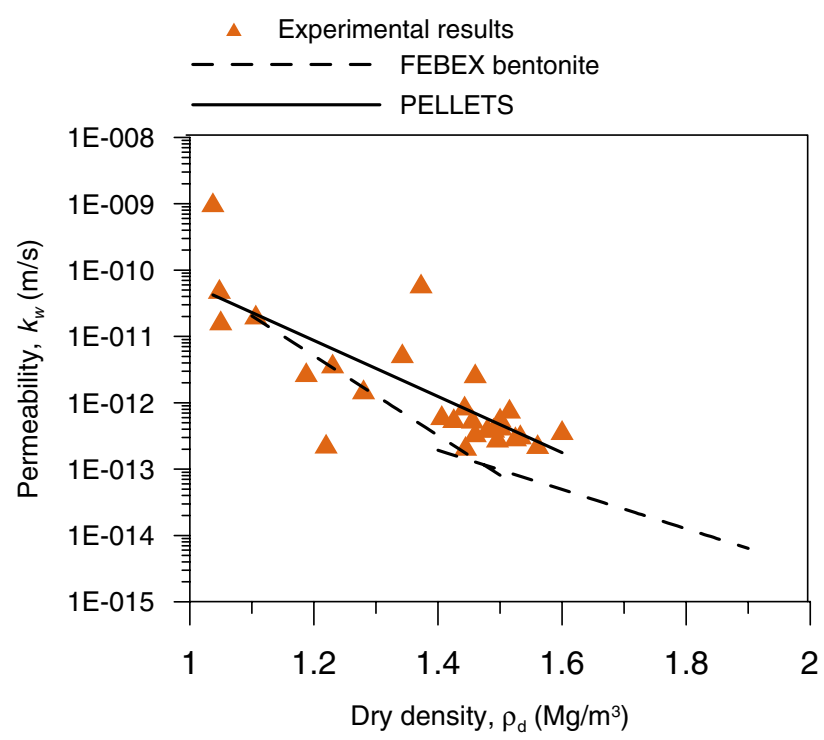

Fig. 9. Saturated permeability of bentonite pellet mixtures prepared at different dry density values. 


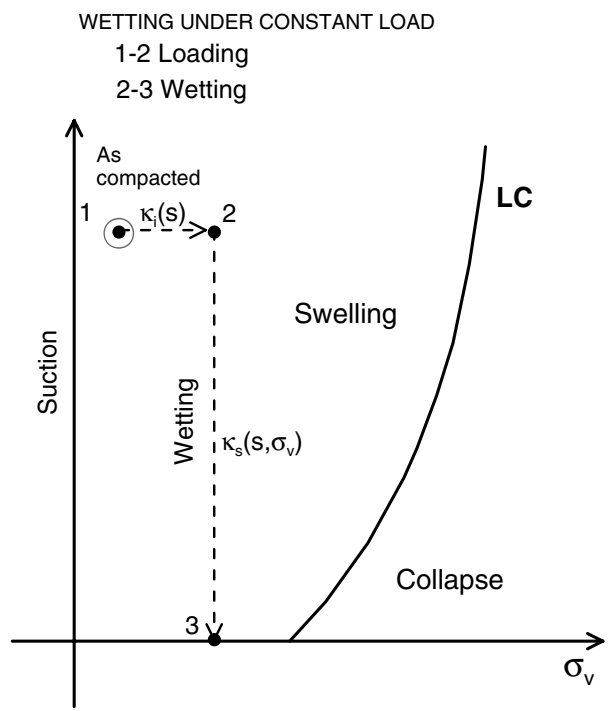

Fig. 10. Stress path followed during wetting at constant load.

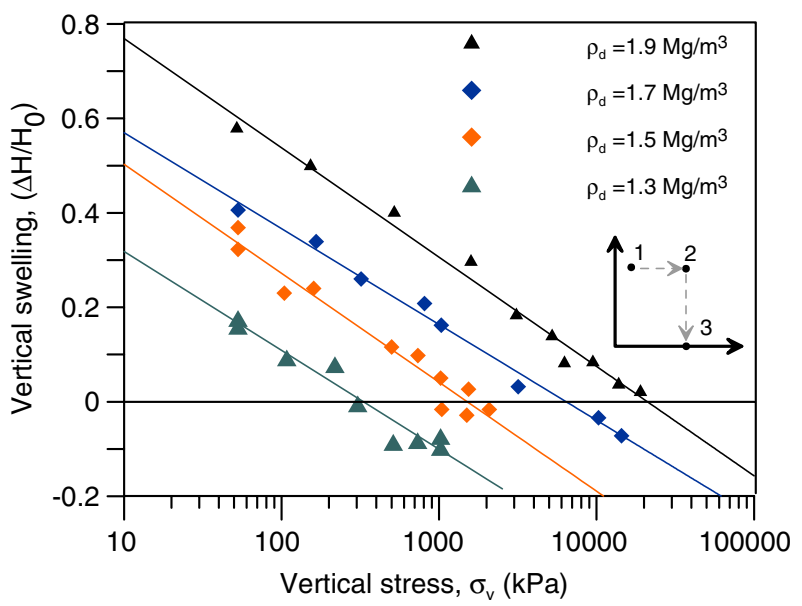

Fig. 11. Results obtained during wetting at constant load tests performed on samples with dry density values of $1.3,1.5,1.7$ and $1.9 \mathrm{Mg} / \mathrm{m}^{3}$.

is obtained. The swelling strain depends linearly on the logarithm of the confining vertical stress. Note also that volumetric compression (collapse) was measured for high confining stresses. The set of results plotted in Fig. 11 may be described by the regression function

$\varepsilon_{\mathrm{v}}=0.094 \ln \left(\sigma_{\mathrm{v}}\right)-0.732 \rho_{\mathrm{d}}+0.416$

where $\varepsilon_{\mathrm{v}}$ is the volumetric deformation $\left(\varepsilon_{\mathrm{v}}=-\frac{\Delta H}{H_{0}}\right.$, negative values indicate swelling $),\left(\sigma_{\mathrm{v}}\right)$ is the total confining vertical stress $[\mathrm{kPa}]$ and $\rho_{\mathrm{d}}$ is the dry density $\left[\mathrm{Mg} / \mathrm{m}^{3}\right]$. Considering the expression (3) and setting $\varepsilon_{\mathrm{v}}=0$, an approximation for the swelling pressure of the material can be derived. It is represented as a discontinuous line in Fig. 13.

Wetting under constant volume tests were performed on samples prepared at dry density values varying from 1.2 to $1.7 \mathrm{Mg} / \mathrm{m}^{3}$. Typical stress paths followed during these tests are illustrated in Fig. 12. The yield locus LC represents the overconsolidation pressure at different suction values and it

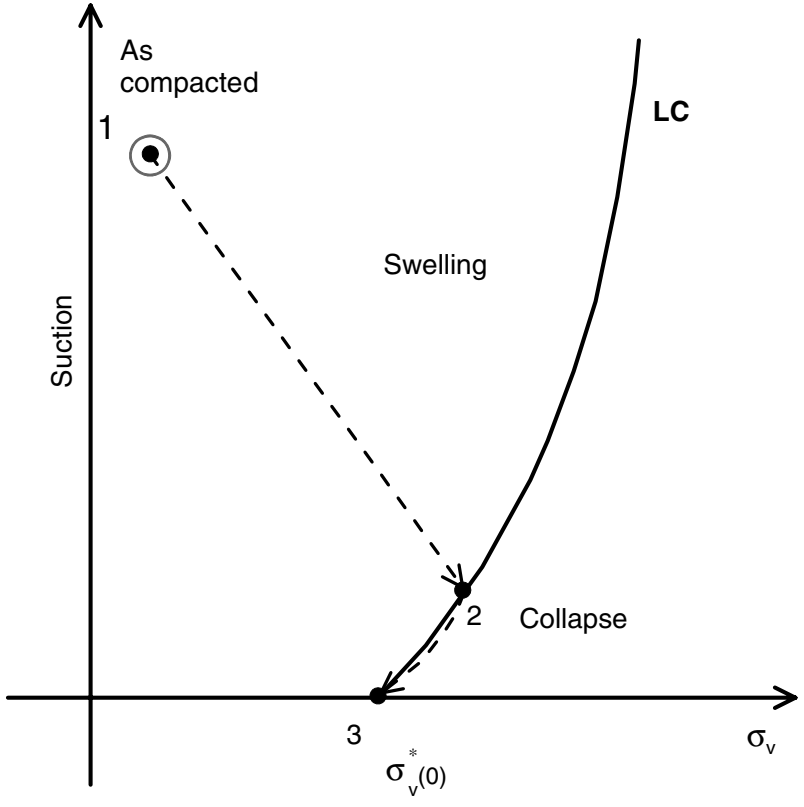

Fig. 12. Stress path followed during wetting at constant volume.

is associated with the intergranular forces holding the granular packing stable. The vertical swelling pressure was defined as the vertical stress measured at the end of the test and it is indicated as point 3 in Fig. 12. Note that the stress path 1-2-3 plotted may imply some intermediate peak swelling pressure (point 2) which was not recorded in these tests.

Results are presented in Fig. 13 together with values reported for the FEBEX bentonite (ENRESA, 2000) and also the approximate swelling pressure derived from swelling under load tests (Eq. (3) with $\varepsilon_{\mathrm{v}}=0$ ). Good agreement is observed between pellet's mixtures and the results obtained for compacted FEBEX bentonite. The conclusion is that the initial water content (which varies between $4 \%$ and $14 \%$ in the specimens represented in Fig. 13) does not affect the swelling potential. Lower swelling pressure values are derived from the wetting under constant load

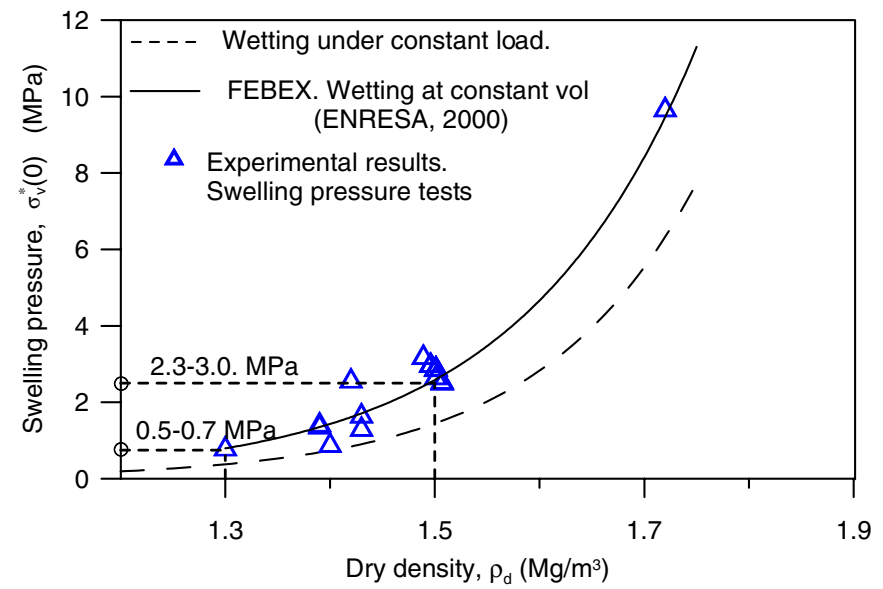

Fig. 13. Variation of swelling pressure with dry density. 
tests (refer to Fig. 11) and this indicates that the swelling pressure depends on the actual stress path followed by the specimen. In other words, the swelling pressure is not a well defined material property as it has been often indicated.

\subsection{Hydraulic response during wetting}

The estimation of the total time required for the engineering barrier to reach an almost saturated state and the total amount of water incorporated during this process are relevant aspects of barrier design. An adequate answer to these questions requires the investigation of the hydromechanical response of the material during the hydration process. In fact, the saturation process appears to be a strongly coupled hydro-mechanical phenomenon, controlled by the boundary conditions and characterized by strong structural changes, which modify the granular pellet material. During hydration, the pellet mixtures evolve from an almost granular structure having a high-interconnected interpellet porosity network, to a more homogenous material where the initial high-density expansive granules could be hardly distinguished. Fig. 14 shows different views of a bentonite pellet samples at different degrees of saturation. The marked initial double porosity and the highly expansive nature of the pellets are of fundamental importance to understand the hydraulic and mechanical properties of the mixture.

In order to gain insight into the hydro-mechanical response of the material during wetting, different tests were designed. Infiltration tests were performed in order to obtain information about the evolution of the water content with suction and about the relationship between water permeability and the degree of saturation. The mechanical response was investigated by means of suction controlled oedometer tests (loading at constant suction and wetting at constant load). Parameters have been derived for a modified version of the constitutive law described in Alonso et al. (1990) (BBM: Barcelona Basic Model).

\subsubsection{Water retention curves}

Water content-suction relationships were derived from wetting at constant volume tests performed on samples prepared at dry density values of $1.3,1.5$ and $1.9 \mathrm{Mg} / \mathrm{m}^{3}$. Suction was controlled in wetting paths starting at a suction of $300 \mathrm{MPa}$. A vapour transfer technique was used to control the suction between 300 to $3 \mathrm{MPa}$. Then the axis translation technique was used to reduce suction values from $3 \mathrm{MPa}$ to zero (saturation).

When vapour transfer is used, suction is imposed by means of a relative humidity control in a closed system. Water molecules migrate in vapour phase from a reference system of known potential to the set of soil pores, until hydro-mechanical equilibrium is achieved. The relative humidity of the reference system was controlled by varying the chemical potential of different types of aqueous solutions. Sulphuric acid solutions and saturated salt solutions were used in the experimental programme. Further details of this technique are described in Romero (2001). Using this technique, the equilibrium is assumed when no mass
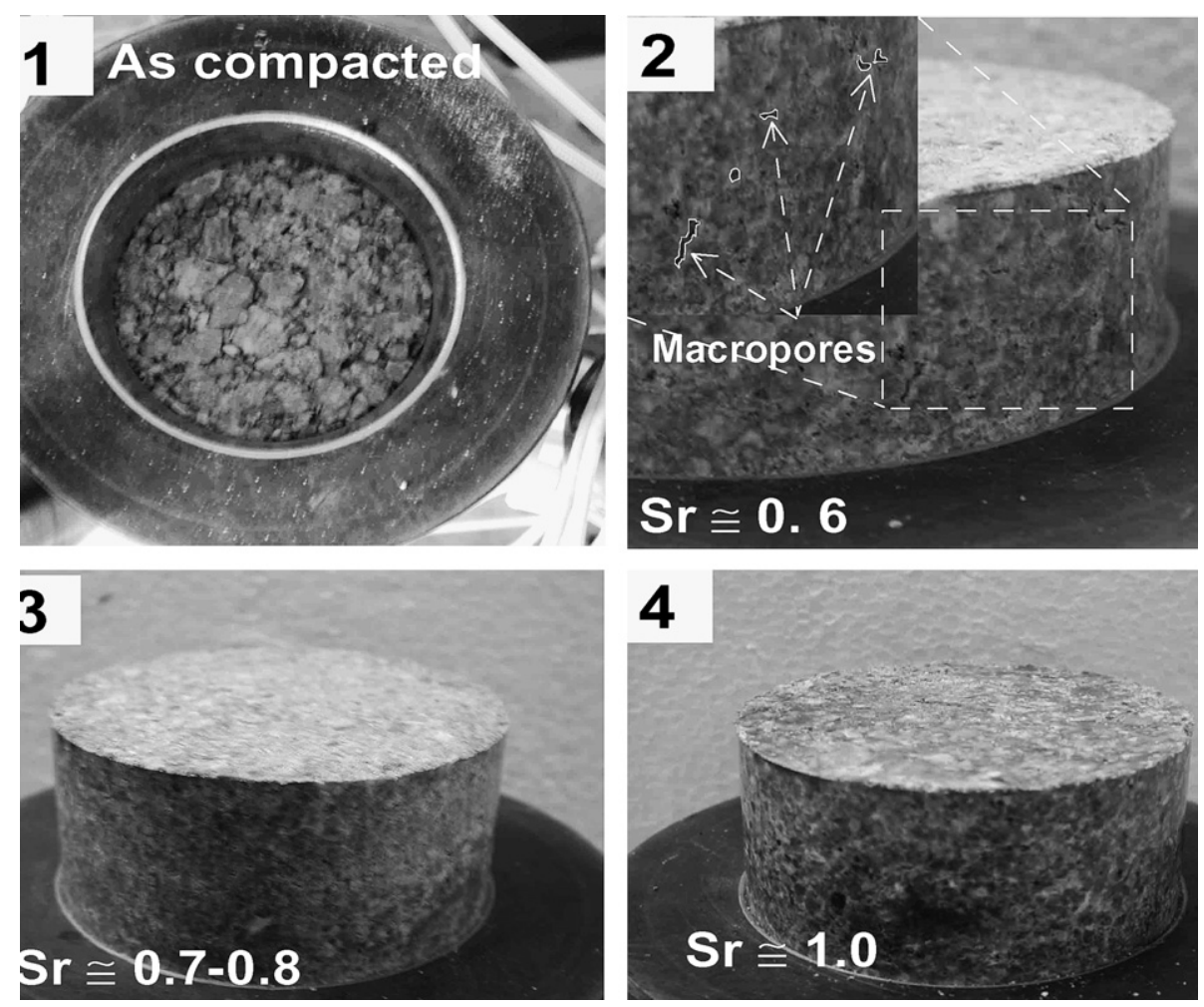

Fig. 14. Evolution of a specimen of bentonite pellets during wetting. 


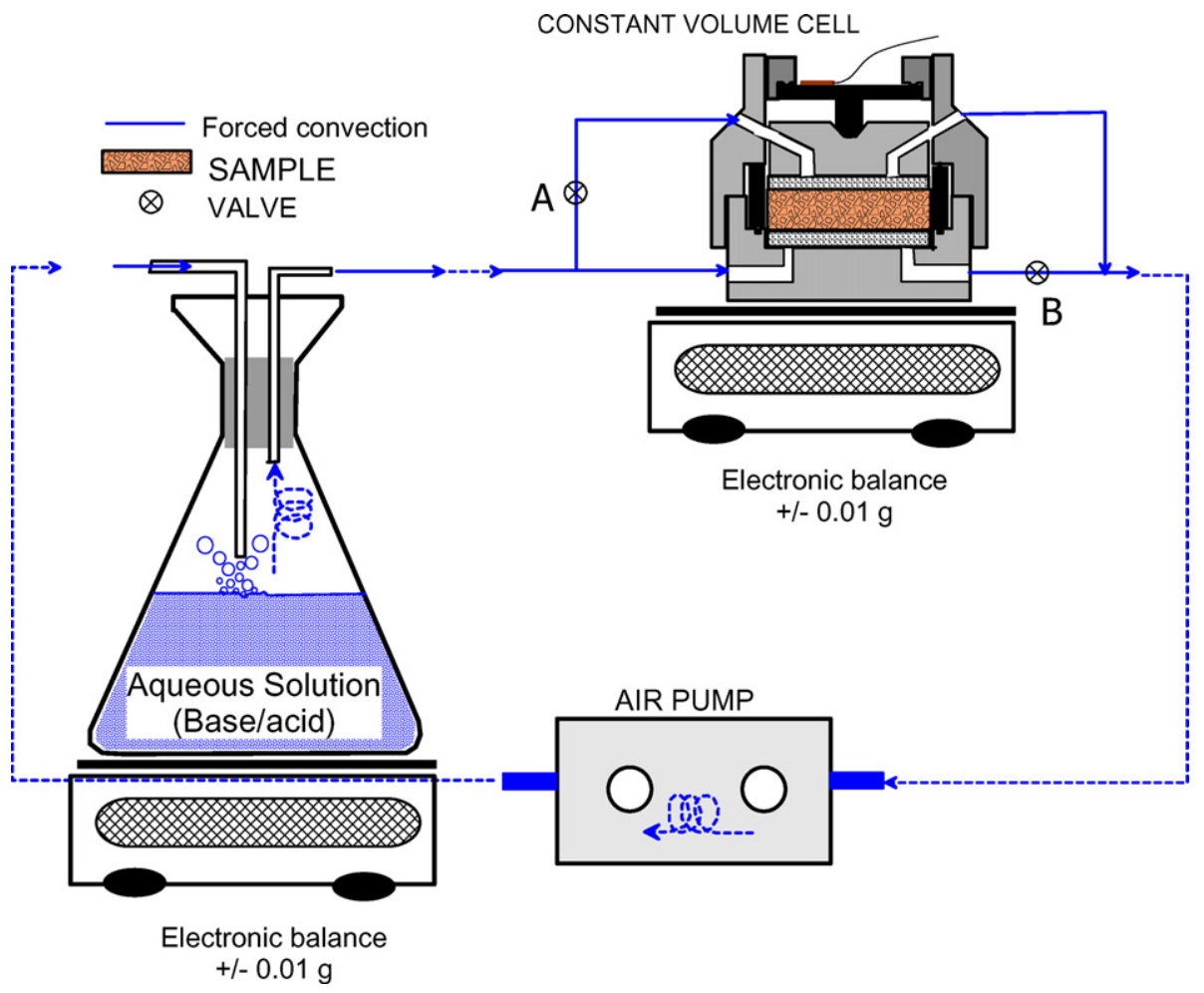

Fig. 15. Oedometer testing device which uses a vapour transfer technique to control suction.

exchange is computed. The testing device used is illustrated in Fig. 15.

When using the axis translation technique gas and water pressure are controlled on the upper and lower porous disks bounding the specimen (Romero, 2001). A scheme of the testing cell and the testing devices is shown in Fig. 16.

Measured water retention data is presented in Fig. 17 for three densities of compacted specimens. Two different zones can be defined in the retention curves. At high suctions the influence of void ratio is found to be negligible in the water content-suction relationships of the compacted mixtures. Water is stored within the granules and water content in the sample is mainly dependent on the specific surface of the clay, the soil microstructure and the pore fluid chemistry. As suction decreases and the water content increases enough to partially fill the inter-pellet

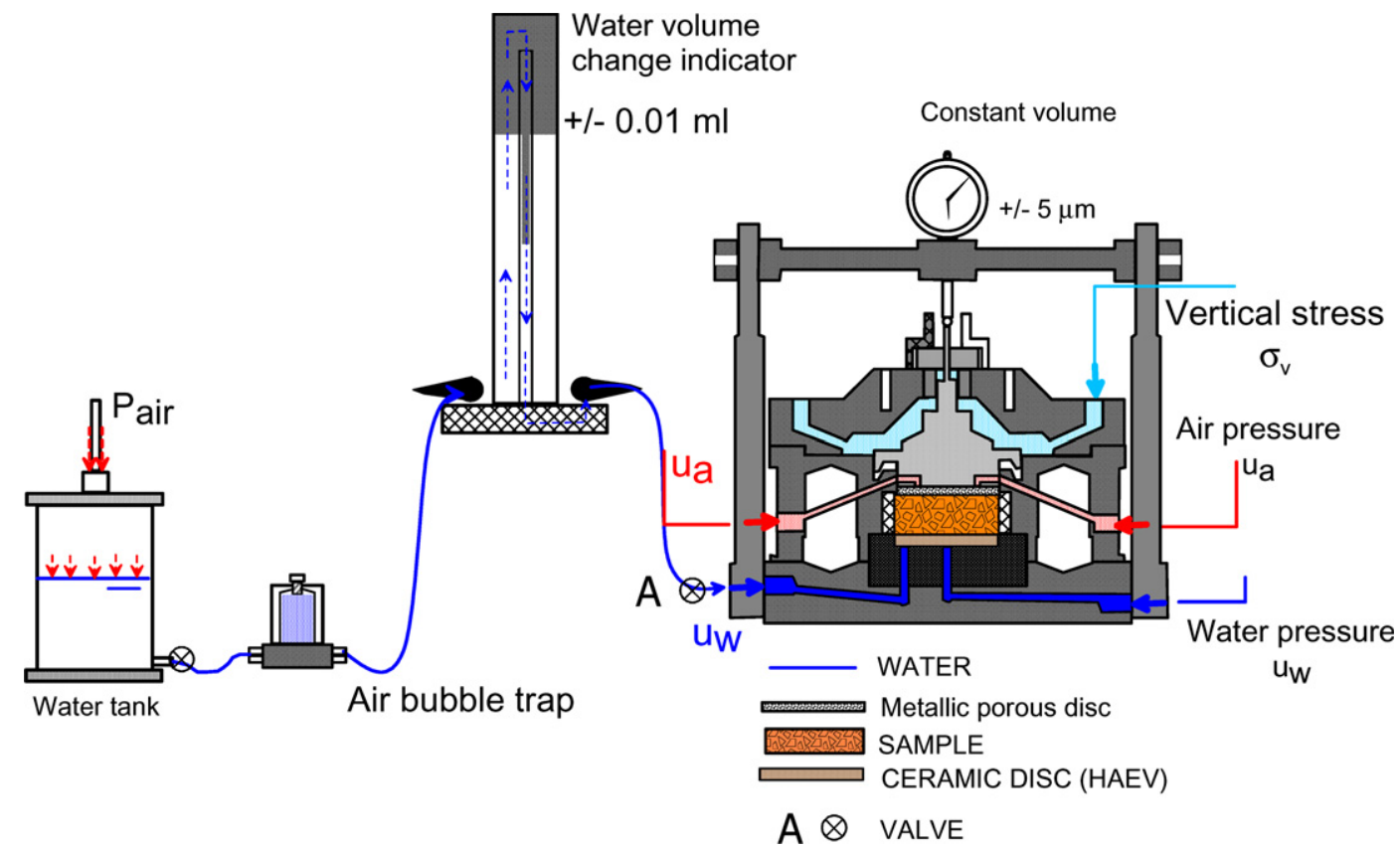

Fig. 16. Oedometer testing device which uses an axis translation technique to control suction. 


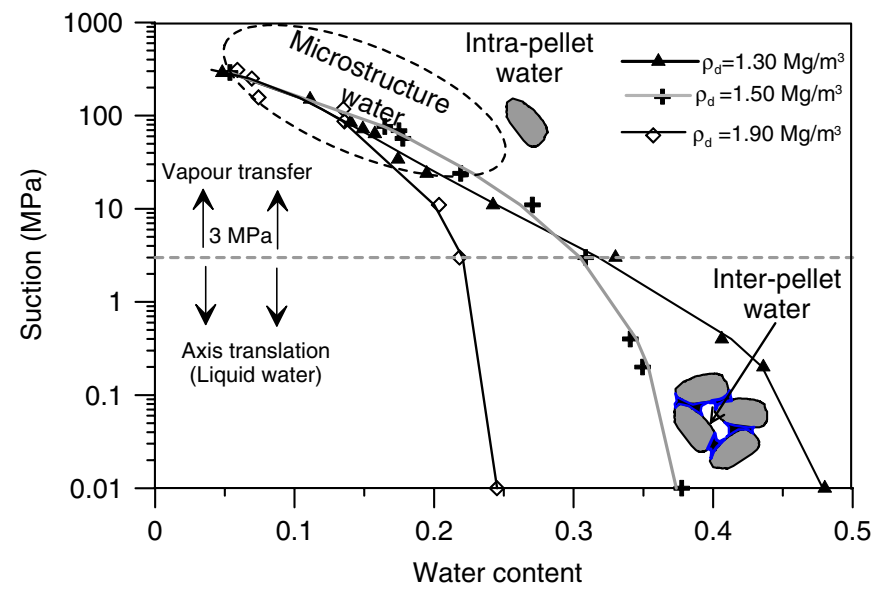

Fig. 17. Water retention curves obtained during wetting at constant volume in samples with dry density values of $1.3,1.5$ and $1.90 \mathrm{Mg} / \mathrm{m}^{3}$.

voids, the suction-water content relationship depends on the void ratio. For modelling purposes, the experimental results were adjusted by means of a modified Van Genuchten law given by

$S_{\mathrm{e}}=\frac{S_{1}-S_{r l}}{S_{s l}-S_{r l}}=\left[1+\left(\frac{P_{\mathrm{g}}-P_{1}}{P_{\mathrm{O}}}\right)^{\frac{1}{1-\lambda}}\right]^{-\lambda} *\left[1-\frac{P_{\mathrm{g}}-P_{1}}{P_{\mathrm{s}}}\right]^{\lambda_{\mathrm{s}}}$

where $S_{r l}$ and $S_{s l}$ are minimum and maximum degree of saturation; $P_{\mathrm{g}}$ and $P_{1}$ are gas and liquid pressure [MPa]; $P_{\mathrm{O}}$ : air entry value $[\mathrm{MPa}] ; \lambda, \lambda_{\mathrm{s}}, P_{\mathrm{s}}[\mathrm{MPa}]$ : experimental parameters.

Table 2

Parameter values for the water retention curves during wetting paths

\begin{tabular}{llll}
\hline Parameter & Value $\left(1.3 \mathrm{Mg} / \mathrm{m}^{3}\right)$ & Value $\left(1.5 \mathrm{Mg} / \mathrm{m}^{3}\right)$ & Value $\left(1.9 \mathrm{Mg} / \mathrm{m}^{3}\right)$ \\
\hline$P_{0}(\mathrm{MPa})$ & 0.95 & 4.15 & 16.6 \\
$\lambda$ & 0.217 & 0.237 & 0.1297 \\
$S_{r l}$ & 0.01 & 0.01 & 0.01 \\
$S_{s l}$ & 1.00 & 1.00 & 1.00 \\
$P_{\mathrm{s}}(\mathrm{MPa})$ & 1000 & 2500 & 3000 \\
$\lambda_{\mathrm{s}}$ & 0.02 & 0.001 & 0.1 \\
\hline
\end{tabular}

Parameter values were obtained by means of a minimum square method and are summarized in Table 2.

\subsubsection{Hydraulic response. Infiltration tests}

Slow and fast infiltration tests were performed in order to investigate the wetting rate on the material response. In the first series of slow tests (INF_SLOW in Table 3), water was injected into the sample using a very low boundary injection pressure $(20 \mathrm{kPa})$. In the second series of fast tests (INF_FAST in Table 3), the boundary pressure was raised to $200 \mathrm{kPa}$.

Samples for the slow infiltration tests $\left(\rho_{\mathrm{d}}=1.5 \mathrm{Mg} / \mathrm{m}^{3}\right.$, $h=50 \mathrm{~mm}$ and $\phi=50 \mathrm{~mm}$ ) were statically compacted $(0.2 \mathrm{~mm} / \mathrm{min})$ directly into the testing cell which was then emplaced into the lever arm oedometer system (Fig. 18). Then, the loading system was positioned on top of the infiltration cell and the lever arm was prevented from moving (in order maintain the constant volume condition) and the resulting force was measured by a load cell.

A series of three different tests varying the total water injection time were performed. Other testing details are summarized in Table 3. The evolution of the volume of water injected during these tests is shown in Fig. 19. Once the water injection was stopped, samples were extracted from the testing cell and then cut into slices in order to obtain a water content profile (Fig. 20).

These results were interpreted by means of a backanalysis procedure using a Hydro Mechanical computer code (CODE_BRIGHT, Alonso and Hoffmann, 2005). An exponential relative permeability law was used to reproduce the observed behaviour

$k_{r l}=A * S_{\mathrm{e}}^{\lambda}$

Optimum values for $A$ and $\lambda$ parameters were found to be $A=1$ and $\lambda=1.9 . S_{\mathrm{e}}$ is given by Eq. (4).

In fast infiltration tests, the inflow and outflow water volumes were monitored. The outflow rate was interpreted as a flow through the interconnected interpellet voids (macropores) of the specimen. The outflow record could then be used to derive the evolution of the Darcy permeability of the mixture. The difference between inflow and outflow is the water stored in the sample (Fig. 21).

Table 3

Characteristics of the infiltration tests

\begin{tabular}{|c|c|c|c|c|c|c|c|c|c|}
\hline \multirow[t]{2}{*}{ Name } & \multirow[t]{2}{*}{$\rho_{\mathrm{d}}\left(\mathrm{Mg} / \mathrm{m}^{3}\right)$} & \multirow[t]{2}{*}{ Test time } & \multirow{2}{*}{$\begin{array}{l}\text { Injection pressure } \\
(\mathrm{kPa})\end{array}$} & \multicolumn{2}{|c|}{ Grain size distribution } & \multicolumn{4}{|c|}{ Measured variables } \\
\hline & & & & $D_{\min }(\mathrm{mm})$ & $D_{\max }(\mathrm{mm})$ & Inflow & Outflow & $\begin{array}{l}\text { Vertical } \\
\text { load }\end{array}$ & $\begin{array}{l}\text { Water } \\
\text { content }\end{array}$ \\
\hline INF_SLOW & 1.5 & $308 \mathrm{~h}$ & 20 & 0.4 & 10 & $\checkmark$ & - & $\checkmark$ & $\checkmark$ \\
\hline$\underset{3}{\text { INF_SLOW }}$ & 1.5 & $525 \mathrm{~h}$ & 20 & 0.4 & 10 & $\checkmark$ & - & $\checkmark$ & $\checkmark$ \\
\hline INF_FAST 2 & 1.3 & $30 \mathrm{~s}$ & 200 & $D=4 \mathrm{~mm}$ & CONST & $\checkmark$ & $\checkmark$ & $\checkmark$ & $\checkmark$ \\
\hline INF_FAST 3 & 1.3 & $45 \mathrm{~s}$ & 200 & $D=4 \mathrm{~mm}$ & CONST & $\checkmark$ & $\checkmark$ & $\checkmark$ & $\checkmark$ \\
\hline INF_FAST 4 & 1.3 & $\begin{array}{l}200 \mathrm{~h} \\
(\mathrm{Sr}=1)\end{array}$ & 200 & $D=4 \mathrm{~mm}$ & CONST & $\checkmark$ & $\checkmark$ & $\checkmark$ & $\checkmark$ \\
\hline
\end{tabular}




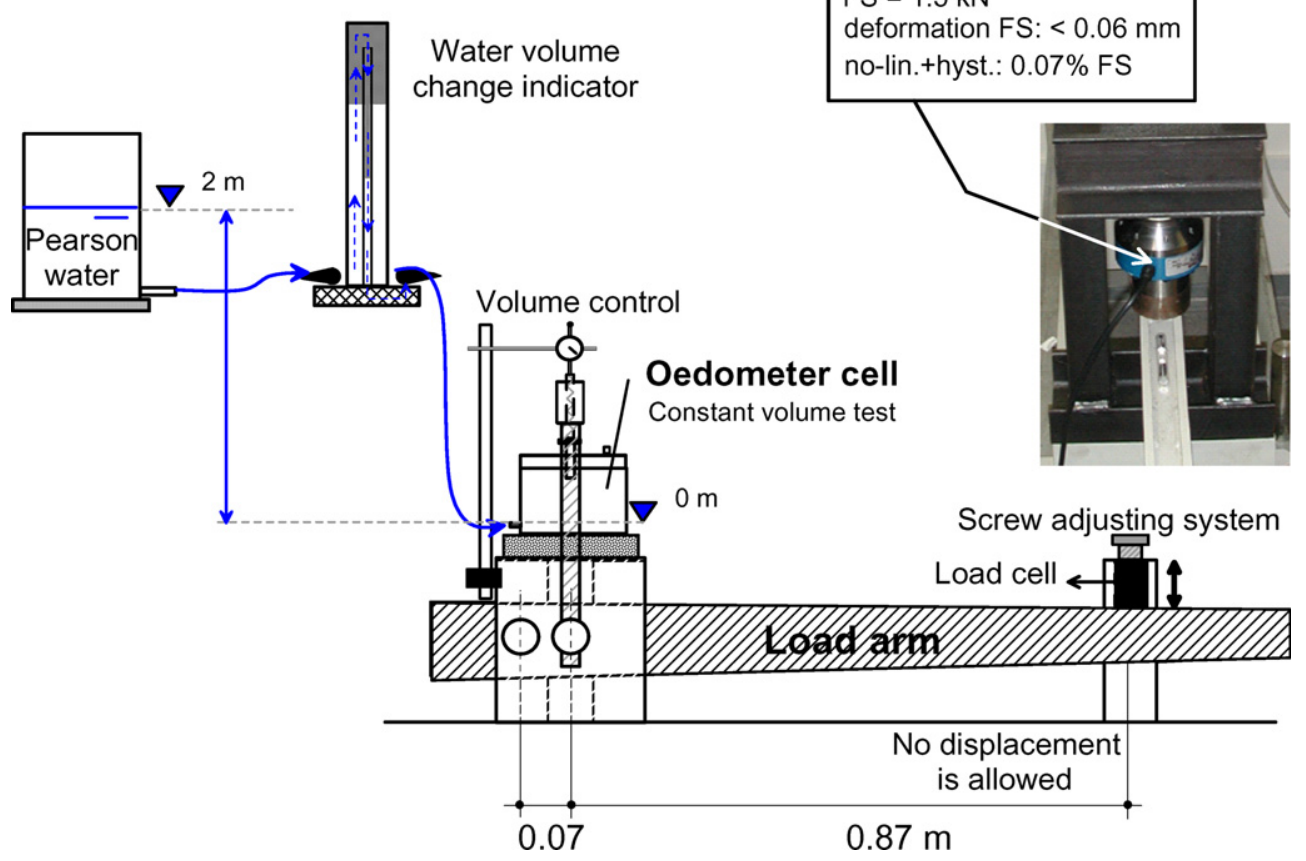

Fig. 18. Testing device used in slow infiltration tests.

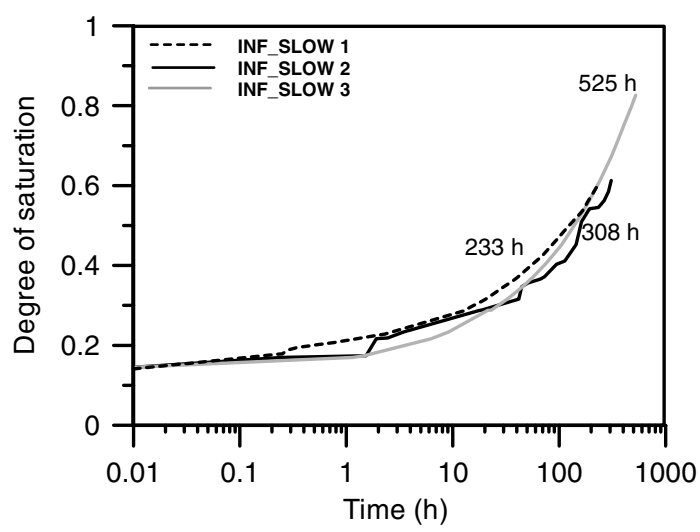

Fig. 19. Evolution of the degree of saturation during slow infiltration tests.

Several tests were performed on identical samples $\left(\rho_{\mathrm{d}}=1.3 \mathrm{Mg} / \mathrm{m}^{3}, \quad h=20 \mathrm{~mm}\right.$ and $\left.\phi=50 \mathrm{~mm}\right)$. Water injection was stopped at different times after the beginning of the test (Table 3). The evolution of the calculated equivalent permeability is shown in Fig. 22a. It can be observed that after a short initial phase where very high permeability values are computed, the permeability decays rapidly and reaches asymptotically the saturated value at the end of the test. The observed behaviour can be explained in terms of the fabric evolution of the bentonite pellet mixtures. At the beginning of the test, the water flows through the initial open interpellet porosity network. After this initial period, the bentonite pellets begin to swell filling the interpellet voids and inducing a fast and strong reduction of the permeability. The change in permeability has been plotted also

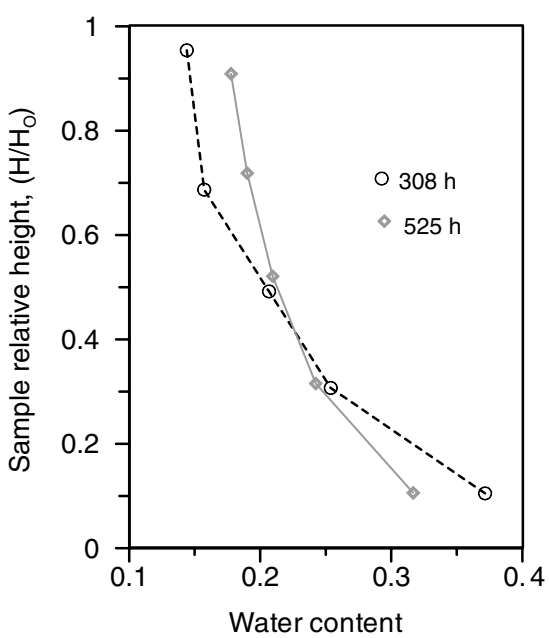

Fig. 20. Water content profiles corresponding to slow infiltration tests.

against the current degree of saturation in Fig. 22b. The plot shows the fast destruction of the open pore network when the degree of saturation increases from 0.6 to 0.7 .

\subsection{Mechanical response during hydration. Suction controlled tests}

\subsubsection{Suction controlled oedometer cell}

A special oedometer cell (Fig. 23) was designed in order to perform suction controlled tests for a wide range of suction values (Hoffmann et al., 2005). The characteristic feature of this new equipment is the possibility of using alternatively the vapour transfer or the axis translation 


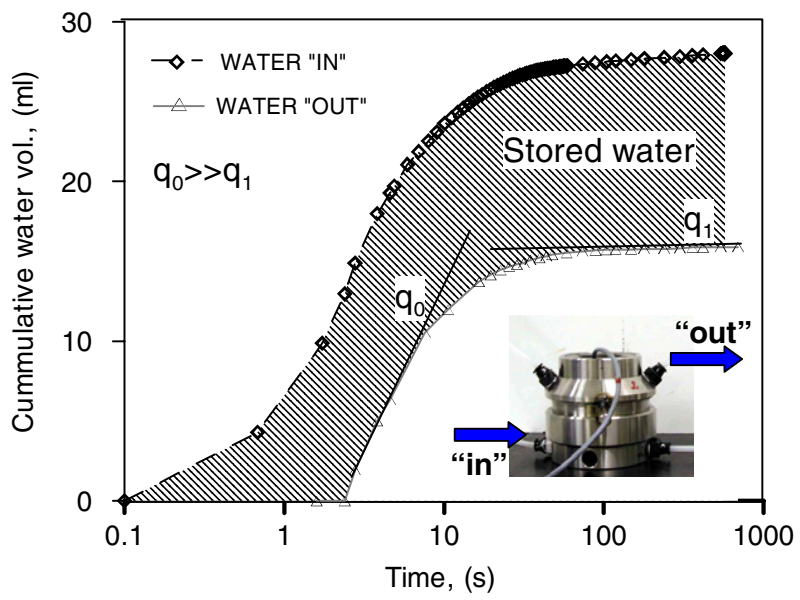

Fig. 21. Evolution of the cumulative inflow and outflow water volumes during fast infiltration tests.
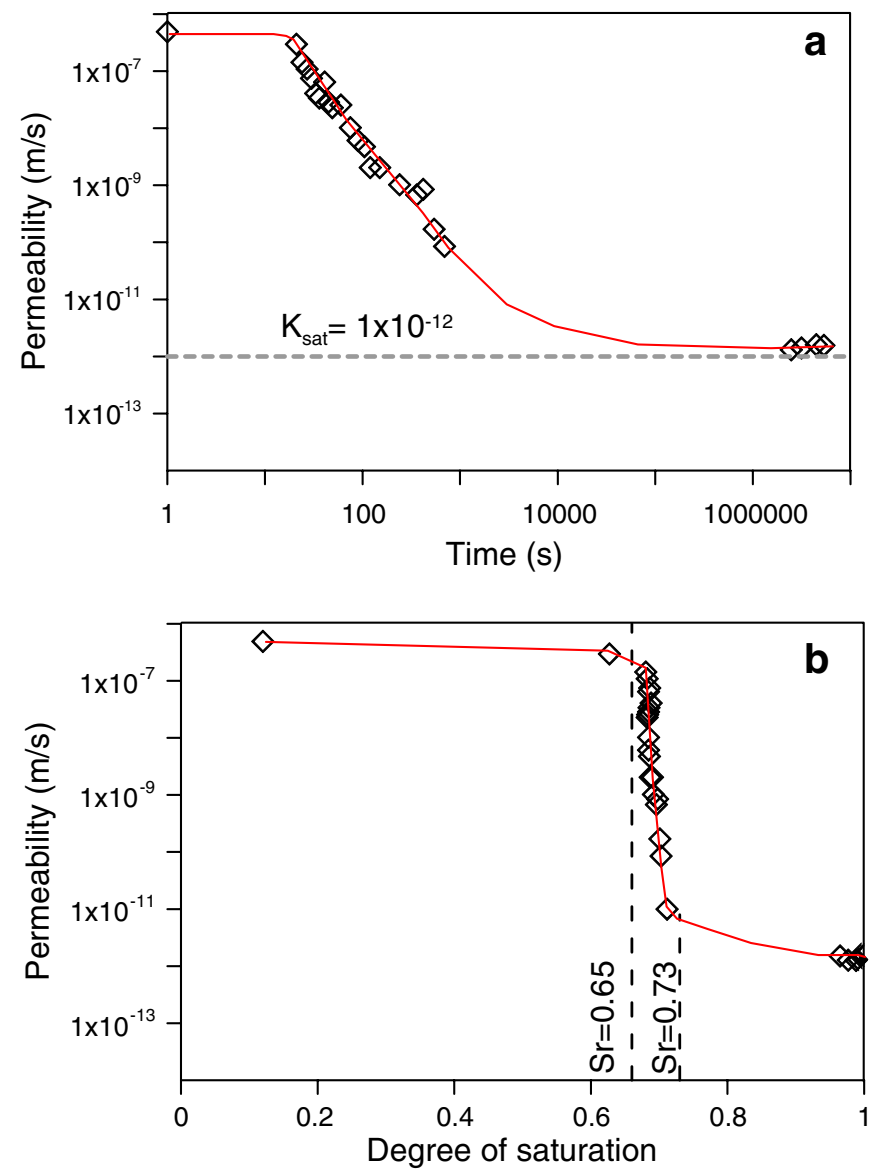

Fig. 22. (a) Evolution of the permeability during fast infiltration tests. (b) Calculated permeability in terms of the degree of saturation.

technique to impose a given suction. According to Romero (2001), Yahia-Aïsa et al. (2001) and Cuisinier (2002), the vapour transfer technique is effective in controlling suction in the range $300-2 \mathrm{MPa}$. The axis translation technique allows suction control in the range from $1.5 \mathrm{MPa}$ to saturation.
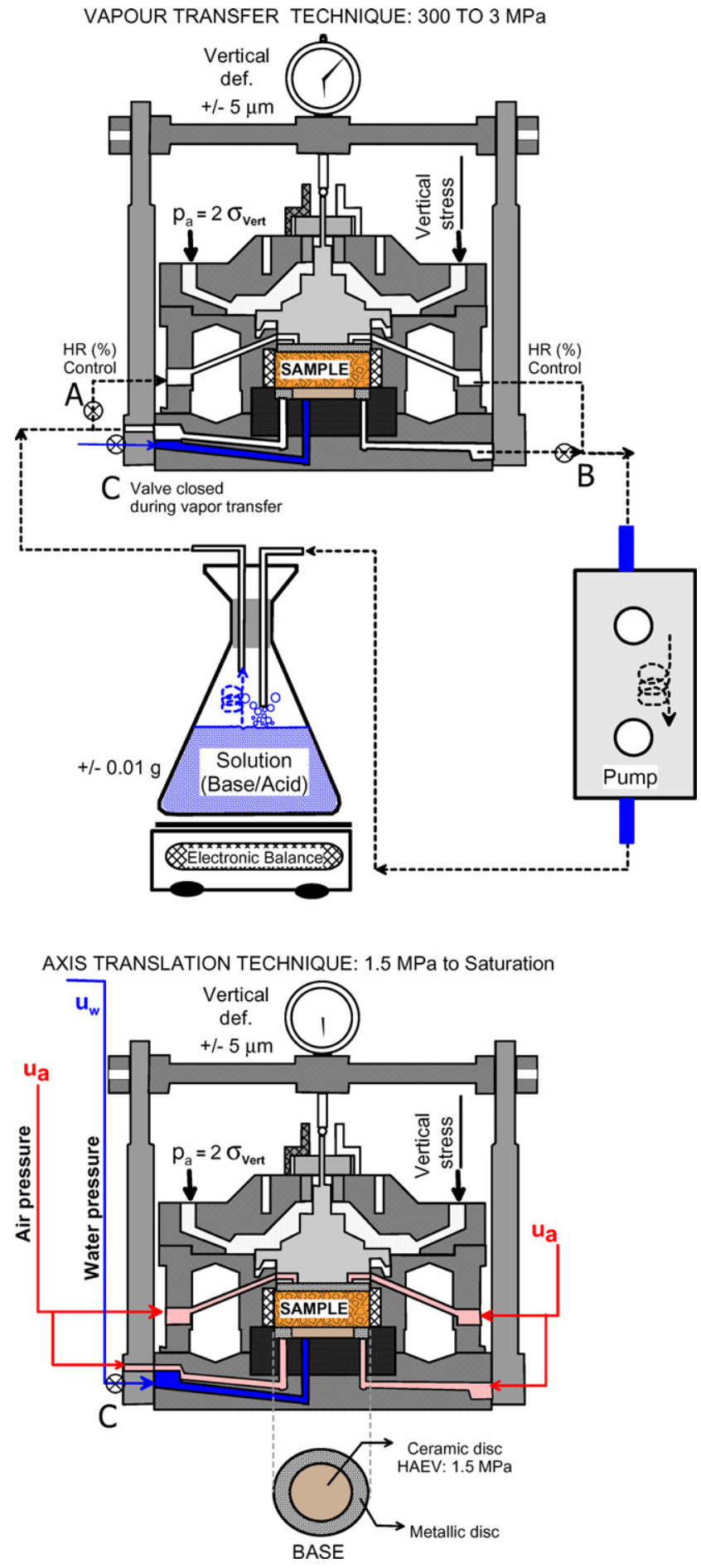

Fig. 23. Testing cell and testing configuration used during suction controlled oedometer tests.

When using the vapour transfer technique, a forced convection system accelerates the water mass exchange between the soil and the saline solution reservoir. When suction control is changed to the axis translation mode the circuit for $\mathrm{RH}$ control is used to apply air pressure (Fig. 23). The design of this equipment is based on a previous prototype described by Di Mariano et al. (2000) to per- 


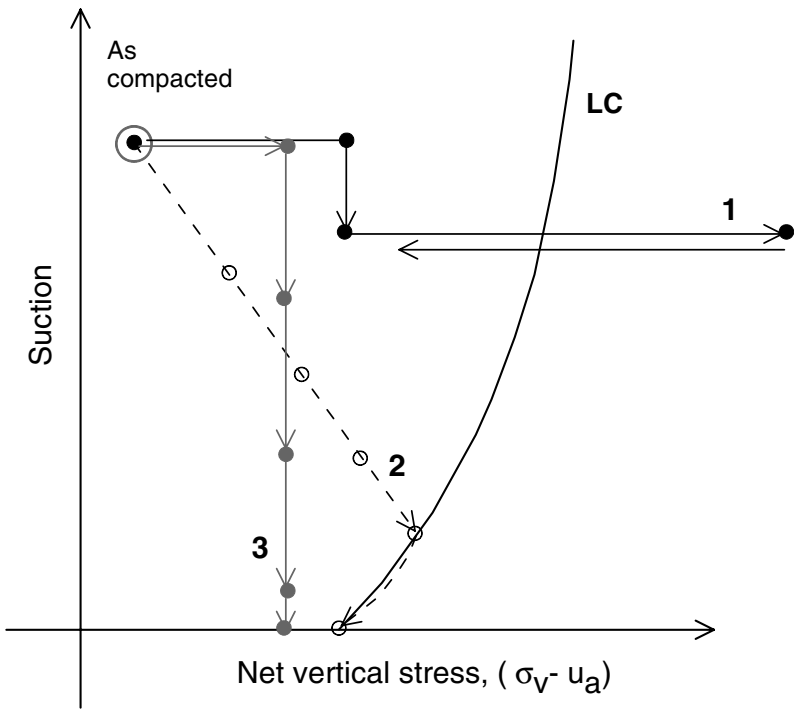

1: Loading at constant suction

2: Wetting at constant volume

3: Wetting at constant load

Fig. 24. Different stress paths applied during suction controlled tests.

form suction controlled tests on expansive clays. Three types of different suction controlled tests were performed: loading at constant suction, wetting at constant load and wetting at constant volume. Stress paths for these tests are sketched in Fig. 24.

\subsubsection{Loading at constant suction}

Loading at constant suction tests were performed on samples prepared at dry density values of $1.3,1.5,1.7$ and $1.9 \mathrm{Mg} / \mathrm{m}^{3}$ in order to examine the evolution of the mixture compressibility with suction and with the initial dry density of the sample. Most tests were performed on samples prepared at 1.3 and $1.5 \mathrm{Mg} / \mathrm{m}^{3}$ (the average emplacement dry density was $1.36 \mathrm{Mg} / \mathrm{m}^{3}$, NAGRA, 2003). Typical compressibility curves obtained during these tests are shown in Figs. 25 and 26. Fig. 25 shows the effect of suction on the material compressibility whereas the effect of the initial dry density is highlighted in Fig. 26.

Based on these tests, the elastic and the elastoplastic compressibility coefficients ( $\kappa_{\text {oed }}$ and $\left.\lambda_{\text {oed }}\right)$, and the apparent yield (overconsolidation) stress for different suctions were derived. Compressibility coefficients and its evolution with suction are presented in Fig. 27. It can be observed that material stiffness decreases as suction decreases. The effect of the confining stress is also apparent in the stiffness parameters. The variation of the yield (overconsolidation) stress with suction is given in Fig. 28 for specimens compacted to $\rho_{\mathrm{d}}=1.3 \mathrm{Mg} / \mathrm{m}^{3}$ and $\rho_{\mathrm{d}}=1.5 \mathrm{Mg} / \mathrm{m}^{3}$. Loading Collapse yield curves which fit the experimental data are also plotted.

Material response was interpreted within the framework of the elastoplastic model proposed by Alonso et al. (1990).
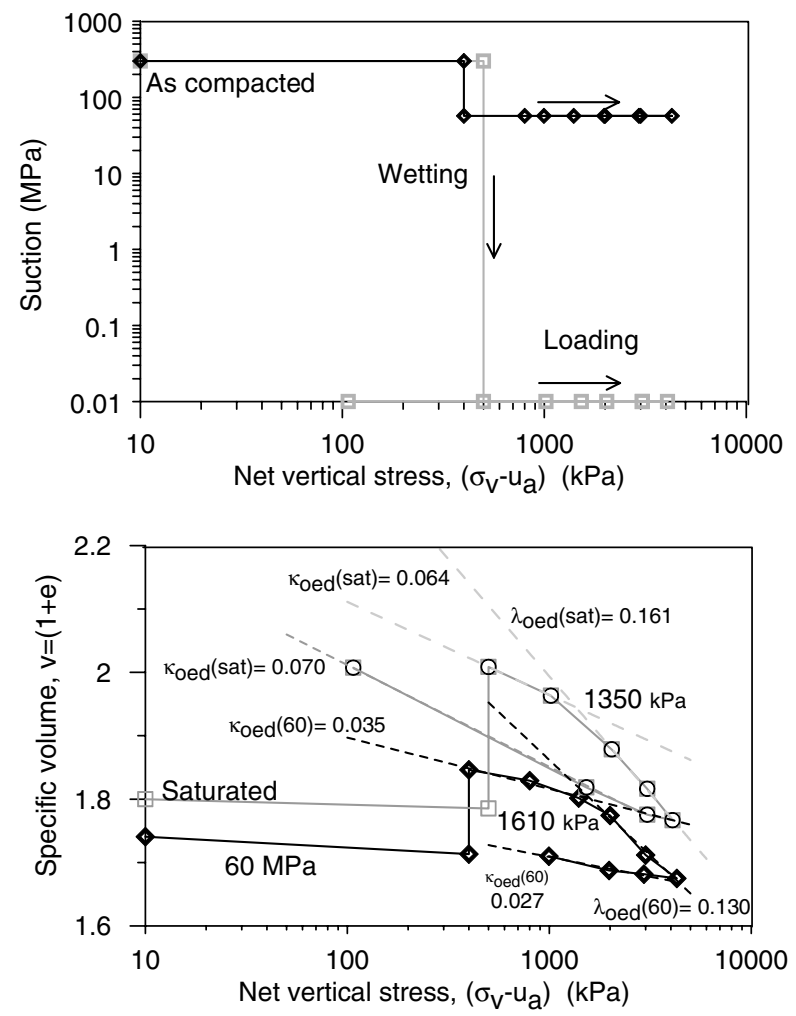

Fig. 25. Effect of suction on material compressibility. Compressibility curves for samples prepared at a dry density of $1.5 \mathrm{Mg} / \mathrm{m}^{3}$.
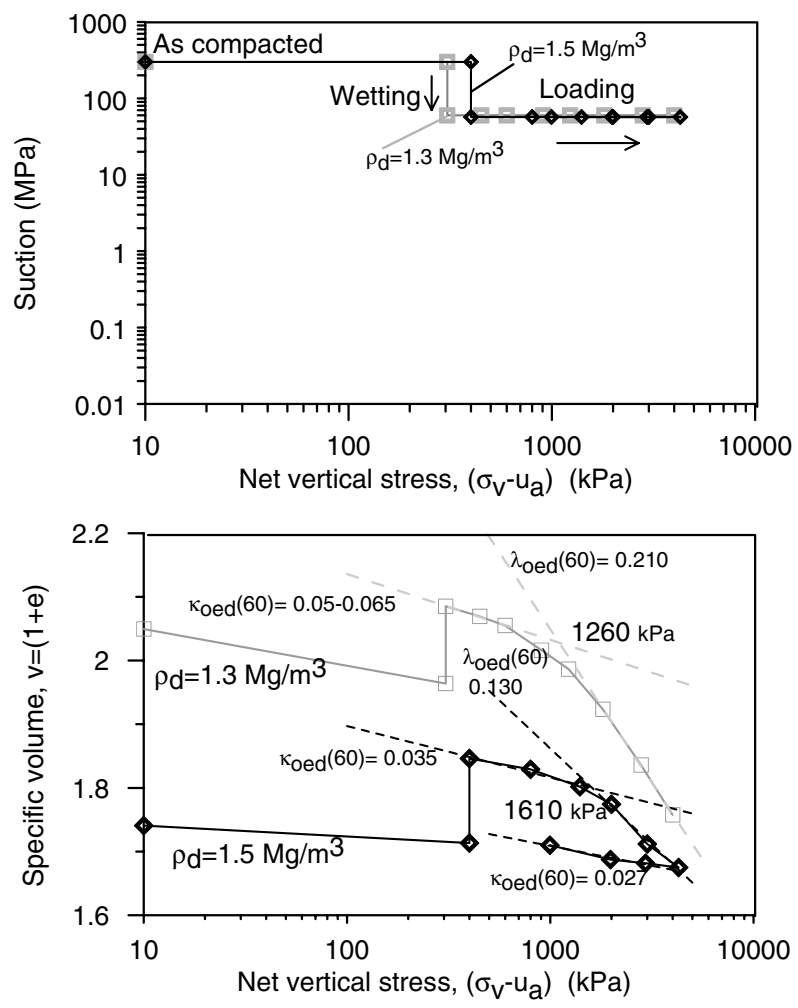

Fig. 26. Effect of initial dry density on material compressibility. Compressibility curves for samples prepared at dry density values of 1.3 and $1.5 \mathrm{Mg} / \mathrm{m}^{3}$. 

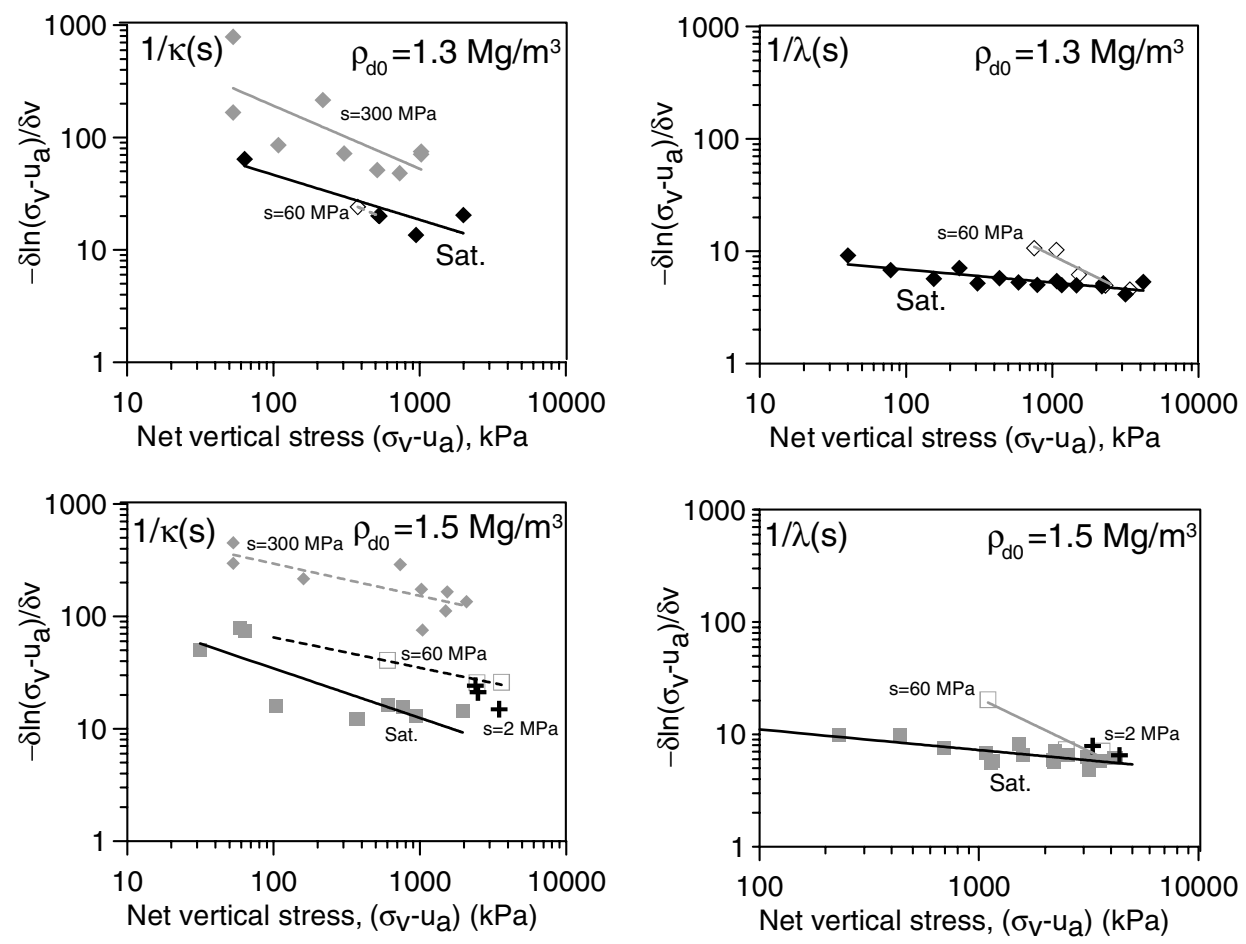

Fig. 27. Evolution of the material stiffness with suction for samples prepared at dry density values of 1.3 and $1.5 \mathrm{Mg} / \mathrm{m}^{3}$.
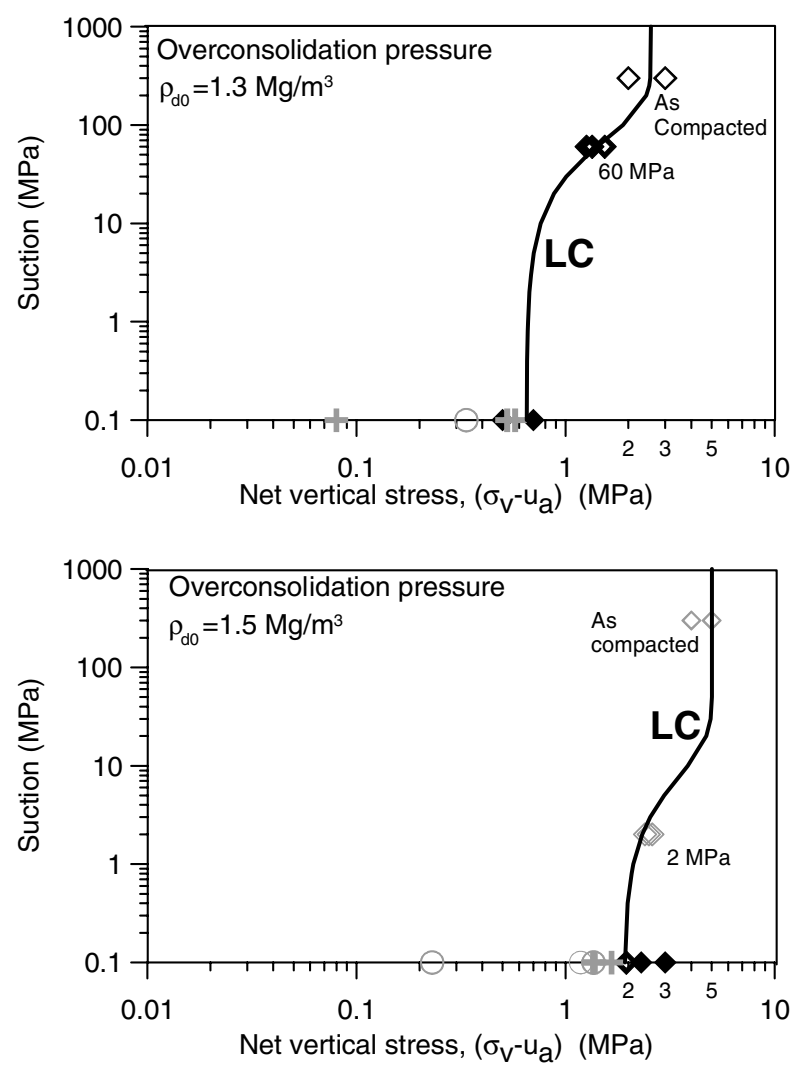

Fig. 28. Evolution of the overconsolidation pressure with suction for samples prepared at dry density values of 1.3 and $1.5 \mathrm{Mg} / \mathrm{m}^{3}$. Loadcollapse (LC) yield surfaces are interpolated through test data.
A summary of the main features of the model is given below:

\subsubsection{Elastic behaviour}

The volume change within the elastic domain is calculated by the following incremental expression:

$\mathrm{d} \varepsilon_{\mathrm{v}}^{\mathrm{el}}=\frac{\mathrm{d} p}{K_{p}}+\frac{\mathrm{d} s}{K_{s}}$

where $K_{p}$ and $K_{s}$ are the coefficients of volume compressibility against changes in net means stress $\left(p=\left(\sigma_{\mathrm{m}}-u_{\mathrm{a}}\right)\right.$; $\sigma_{\mathrm{m}}$ mean stress, $u_{\mathrm{a}}$ : air pressure $)$ and suction $\left(s=\left(u_{\mathrm{a}}-u_{\mathrm{w}}\right)\right.$; $u_{\mathrm{w}}$ : water pressure), respectively. These coefficients are expressed by

$K_{p}=\frac{(1+e) p}{\kappa_{i}}$

$K_{s}=\frac{(1+e)\left(s_{+} p_{\mathrm{atm}}\right)}{\kappa_{s}}$

where $\kappa_{i}$ and $\kappa_{s}$ are parameters of the model, $e$ the void ratio, and $p_{\text {atm }}$ the atmospheric pressure. In practice, these parameters depend on suction and stress level and the following expressions are proposed:

$\kappa_{i}(s)=\kappa_{i 0} *\left(1+\alpha_{i} * s\right)$

and

$\kappa_{s}=\kappa_{s 0}\left[1+\alpha_{s p} \ln \left(\frac{p}{p_{\text {ref }}}\right)\right] \mathrm{e}^{\alpha_{s s} s}$ 


\subsubsection{Yield surfaces under isotropic stress conditions}

The elastic behaviour is limited by means of two yield surfaces. The first one (LC) is associated with the irrecoverable deformations developed during wetting and loading paths

$p_{0}\left(s, p_{0}^{*}\right)=p^{c}\left(\frac{p_{0}^{*}}{p^{c}}\right)^{\frac{\left(\lambda(0)-\kappa_{i 0}\right)}{\left(\lambda(s)-\kappa_{i}(s)\right)}}$

where $p_{0}^{*}$ represents the saturated preconsolidation stress and $\lambda(s)$ is the slope of the virgin compression curve at suction $s$. Parameters $\kappa_{s 0}$ and $\kappa_{s 0}(s)$ are the elastic stiffness parameters for changes in the net mean stress evaluated at a saturated state and at suction $s$ respectively. $p^{c}$ is a reference stress. The model predicts an increase in the soil stiffness as the suction increases given by

$\lambda(s)=\lambda(0) \cdot\left[r+(1-r) \mathrm{e}^{-\beta s}\right]$

where parameters $r$ and $\beta$ control the rate of increase of soil stiffness with suction and $\lambda(0)$ is the slope of the virgin compression curve for saturated conditions.

The second yield surface provides the increase in the tensile strength with suction according to the expression

$p_{s}=-k s$

\subsubsection{Hardening law}

Irrecoverable deformations are computed through the following hardening law:

$\mathrm{d} \varepsilon_{\mathrm{v}}^{\mathrm{pl}}=\frac{\left(\lambda(0)-\kappa_{i 0}\right)}{(1+e)} \frac{\mathrm{d} p_{0}^{*}}{p_{0}^{*}}$

The model is extended to a triaxial state $(p, q)$ by means of elliptical yield surfaces in the deviatoric plane $(p, q) . q$ is the deviatoric stress.

$q^{2}=M^{2}\left(p+p_{s}\right)\left(p_{0}-p\right)$

where $M$ is the limiting critical state slope, which is assumed to be constant.

Derived model parameters are presented in Tables 4 and 5. A comparison between experimental compressibility coefficients and the model functions adopted for compressibility coefficients $\kappa(s)$ and $\lambda(s)$ is shown in Fig. 29.

\subsubsection{Wetting under constant load}

Two wetting under constant load tests following identical stress paths were performed on samples compacted to

Table 4

Parameter values corresponding to the elastic and elastoplastic compressibility coefficients proposed in the BBM model (Alonso et al., 1990)

\begin{tabular}{lccl}
\hline$\rho_{\mathrm{d}}\left(\mathrm{Mg} / \mathrm{m}^{3}\right)$ & $\kappa_{i o}$ & $\alpha_{i}\left(\mathrm{MPa}^{-1}\right)$ \\
\hline Elastic compressibility & $\kappa_{i}(s)=\kappa_{i o} *\left(1+\alpha_{i} * s\right)$ & \\
1.30 & 0.074 & -0.00294 \\
1.50 & 0.064 & -0.0031 \\
$\rho_{\mathrm{d}}\left(\mathrm{Mg} / \mathrm{m}^{3}\right)$ & $\lambda(0)$ & $r$ & $\beta\left(\mathrm{MPa}^{-1}\right)$ \\
\hline Elastoplastic compressibility $\lambda(s)=\lambda(0)[(1-r) \exp (-\beta s)+r]$ \\
1.30 & 0.200 & 0.7 & 0.008 \\
1.50 & 0.165 & 0.855 & 0.150 \\
\hline
\end{tabular}

Table 5

Parameter values obtained for the yield surface fitted considering the overconsolidation pressure values

\begin{tabular}{lll}
\hline$\rho_{\mathrm{d}}\left(\mathrm{Mg} / \mathrm{m}^{3}\right)$ & $\sigma_{\mathrm{v} 0}^{*}(\mathrm{MPa})$ & $\sigma_{\mathrm{c}}(\mathrm{MPa})$ \\
\hline
\end{tabular}

LC yield surface $\sigma_{\mathrm{v}}^{*}(s)=\sigma_{\mathrm{c}}\left(\frac{\sigma_{\mathrm{v} 0}^{*}}{\sigma_{\mathrm{c}}}\right)^{\frac{\lambda(s)-\kappa i o}{\lambda(s)-k i(s)}}$

1.30

1.50

0.65

1.9

0.075

0.09

1.3 and $1.5 \mathrm{Mg} / \mathrm{m}^{3}$. The stress path is indicated in Fig. 30. After a first loading step to $300 \mathrm{kPa}$ (indicated as 1-2 in Fig. 30) at a constant suction of $300 \mathrm{MPa}$, a step by step wetting path was applied using the vapour transfer technique. Starting form an initial value of $300 \mathrm{MPa}$, suction was decreased by means of different aqueous solutions until a $s=3 \mathrm{MPa}$ value was reached. Each suction step was maintained until neither volume change nor mass change were registered in the sample. Once the minimum suction value of $3 \mathrm{MPa}$ was reached, liquid water was finally injected to achieve the saturated condition in a single wetting step. The evolution of volumetric deformations as the wetting progresses is represented in Figs. 31a and 32a for samples having a dry density of 1.5 and $1.3 \mathrm{Mg} / \mathrm{m}^{3}$ respectively.

Net volumetric expansions are computed during the initial wetting steps of both tests because of the swelling of the bentonite pellets. As the suction decreases, different responses are observed for both densities. Volumetric expansions are always recorded for the dry density sample of $1.5 \mathrm{Mg} / \mathrm{m}^{3}$. However, the lighter specimen shows a reversal in the swelling trend (Fig. 32a). It is interpreted that during the initial wetting steps the capillary forces holding together the granular structure are strong enough to keep the structure stable and an overall expansion is computed because of pellet swelling. As the wetting advances, the intergranular forces became reduced or even destroyed because of suction decrease and a macrostructural collapse may overcome the swelling strains associated with pellet hydration. This is the case of the lighter specimen $\left(1.3 \mathrm{Mg} / \mathrm{m}^{3}\right)$ when suction reaches values below $10 \mathrm{MPa}$.

This process can be interpreted in terms of the BBM model. In the case of the denser specimen $\left(\rho_{\mathrm{d}}=1.5 \mathrm{Mg} /\right.$ $\mathrm{m}^{3}$ ) the stress path followed is developed within the elastic domain and net volumetric expansions are computed all along the wetting path, Fig. 31b. In the second specimen $\left(\rho_{\mathrm{d}}=1.3 \mathrm{Mg} / \mathrm{m}^{3}\right)$, the yield curve is closer to the imposed path. After an initial elastic stretch where swelling deformations are computed, the stress path hits the yield surface and a collapse of the granular structure occurs, Fig. 32b. The volumetric deformation at the end of the test is, however, a net expansion.

\subsubsection{Wetting at constant volume tests (swelling pressure tests)}

In order to gain additional insight into the swelling properties of the mixture, controlled wetting under 

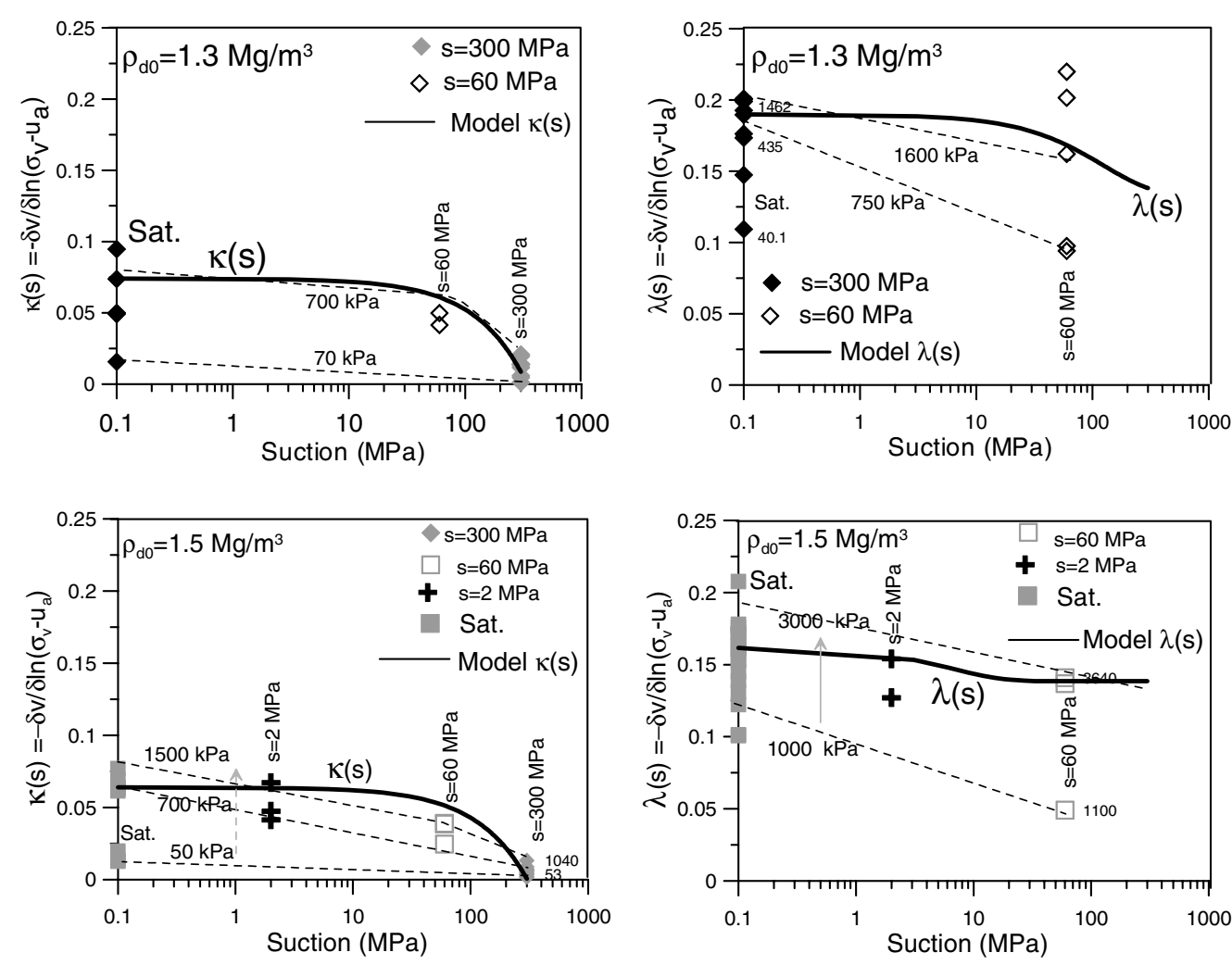

Fig. 29. Elastic and elastoplastic compressibility coefficients derived from tests performed on samples prepared at dry density values of 1.3 and $1.5 \mathrm{Mg} / \mathrm{m}^{3}$.

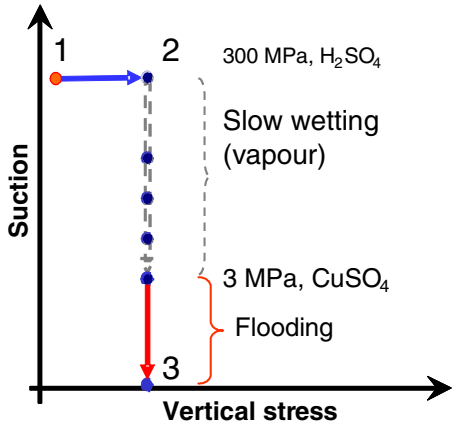

1-2 Loading to $0.3 \mathrm{MPa}$

\section{2-3 Suction controlled wetting in two stages (300MPa to $3 \mathrm{MPa}$; $3 \mathrm{MPa}$ to saturation)}

Fig. 30. Stress path and test characteristics of wetting under constant load tests.

constant volume tests were performed on specimens having dry densities of 1.3 and $1.5 \mathrm{Mg} / \mathrm{m}^{3}$. The stress path is schematically plotted in Fig. 33. As in previous tests, the vapour transfer technique was first used to apply a stepby-step wetting from 300 to $3 \mathrm{MPa}$. Once this value was reached, samples were soaked with water to reach saturation in a single wetting step.

The recorded vertical stress and water content changes as suction is decreased are shown in Fig. 34 for a $1.3 \mathrm{Mg} / \mathrm{m}^{3}$ specimen. Water content could be calculated because the reservoir containing the aqueous solution was continuously weighted. Starting from an initial suction value of $300 \mathrm{MPa}$, the following total suction steps were applied: $\quad 90 \rightarrow 72 \rightarrow 63 \rightarrow 32 \rightarrow 24 \rightarrow 11 \rightarrow 3 \mathrm{MPa}$ prior to the final flooding event. Each equalization stage was maintained until hydraulic and mechanical equilibrium was achieved. Each one of the steps lasted typically 14 days. The data shown in Fig. 34 was collected during 3 months. The highest swelling pressure increment is developed in the first wetting stage and it maintains a nearly constant value on further suction decrease. However, a small reduction was detected when suction decreased below $32 \mathrm{MPa}$.

The observed behaviour can be explained considering the occurrence of two concurrent phenomena: the expansion of the pellets and the evolution of the intergranular forces upon wetting. Initially, when suction is reduced the bentonite granules swell and a net pressure increment is developed to maintain a constant volume condition. During this initial stage the stress path is in the elastic region far from the LC yield locus which describes the yielding of the granular fabric. It is interpreted that the intergranular forces are strong enough to keep the granular arrangements stable and no collapse is produced. However, as wetting progresses, contact between granules decrease in strength and stiffness, the intergranular forces decrease and the overall structure is prone to undergo collapse. Both phenomena coexist during the wetting path. An essentially 

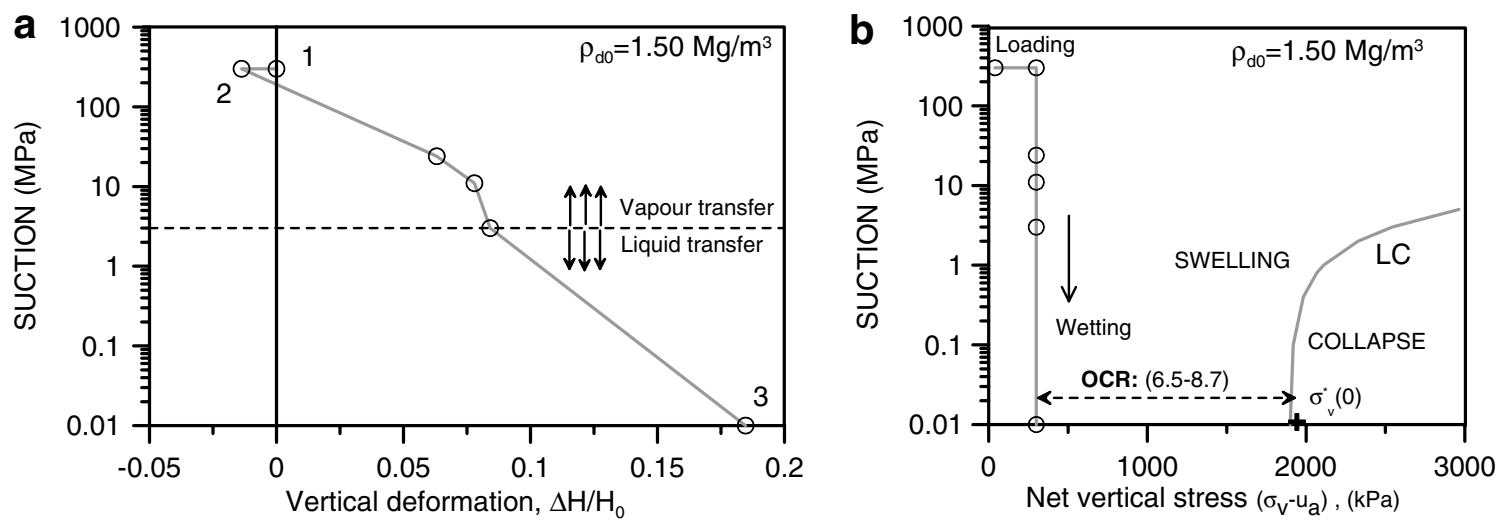

Fig. 31. (a) Vertical deformation during wetting under constant load for a sample having a dry density of $1.5 \mathrm{Mg} / \mathrm{m}^{3}$. (b) Stress path and assumed position of the LC yield curve.
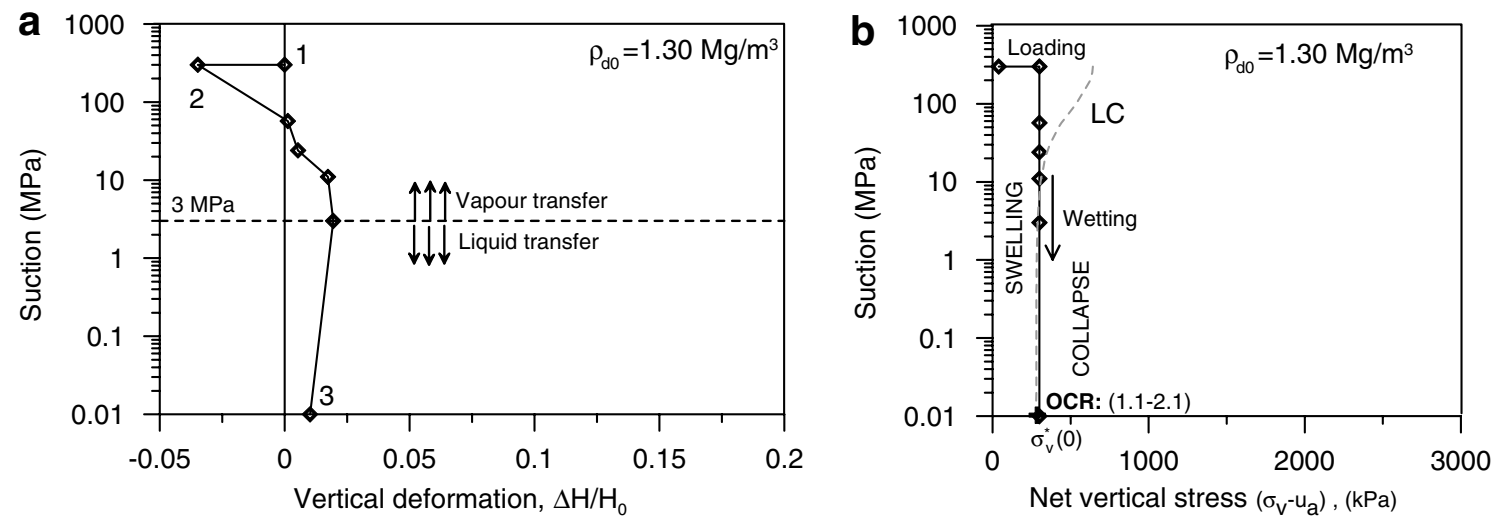

Fig. 32. (a) Vertical deformation during wetting under constant load for a sample having a dry density of $1.3 \mathrm{Mg} / \mathrm{m}^{3}$. (b) Stress path and position of the LC yield curve.

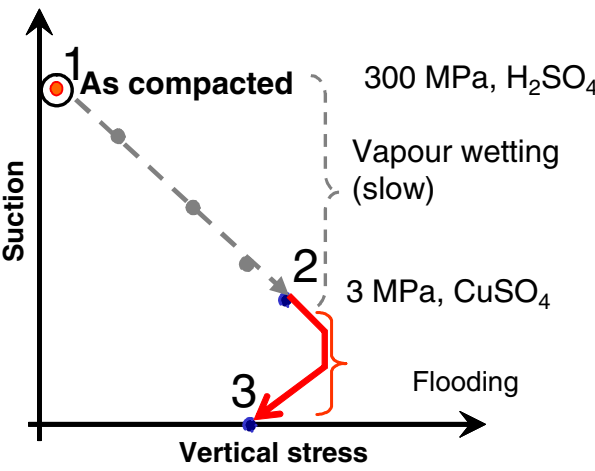

1-2 Multi-stage wetting.

\section{2-3 Fast flooding}

Fig. 33. Stress path and test characteristics of wetting at constant volume tests.

constant swelling pressure represents a balance between them. The stress path follows approximately the LC yield curve. Fig. 35 shows a plot of the swelling pressure evolu-

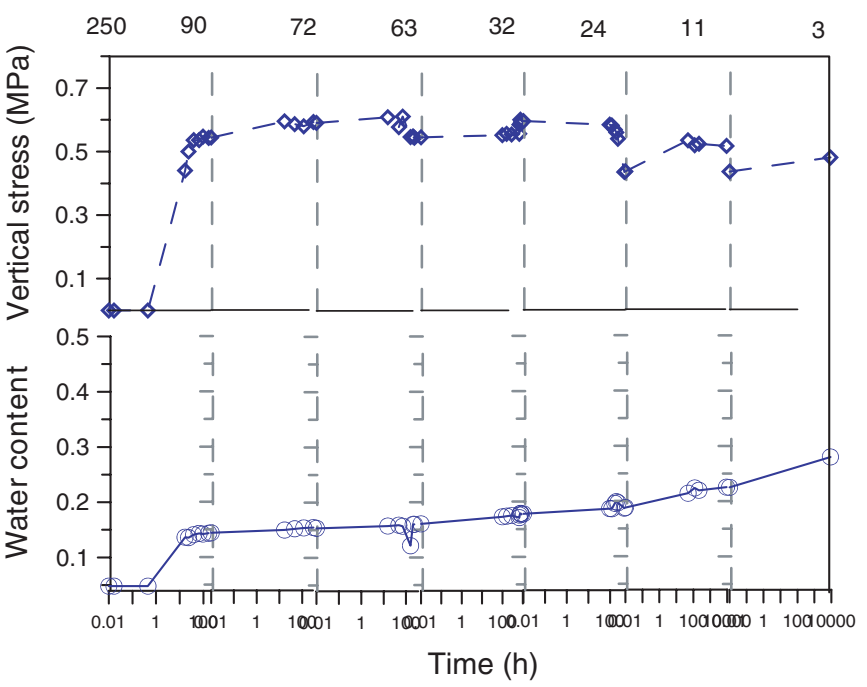

Fig. 34. Recorded evolution of vertical swelling pressure and water content of specimen having $\rho_{\mathrm{d}}=1.3 \mathrm{Mg} / \mathrm{m}^{3}$ during wetting at constant volume. Suction is indicated in the upper part of the figure.

tion during wetting for the two different dry densities tested. 

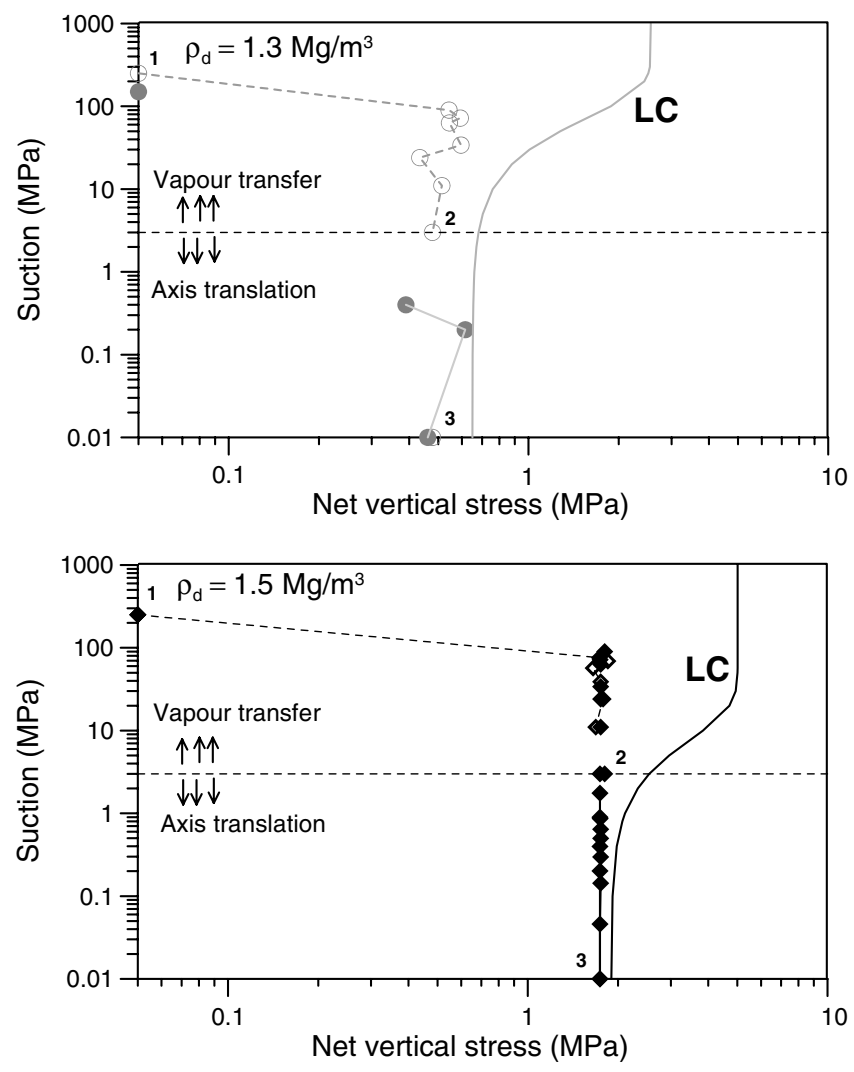

Fig. 35. Stress paths of swelling pressure tests.

\section{Summary and conclusions}

Within the context of the Engineering Barrier Emplacement Experiment (EB Project), a material made of bentonite pellets is being suggested as a suitable alternative for the construction of isolating barriers in deep HWL repositories. Ease of handling is an often mentioned advantage of using this material. The project includes two main experimental activities, a real scale test and a laboratory testing programme performed to characterize the hydro-mechanical response of bentonite pellet's mixtures.

This paper reports the results obtained within the laboratory testing programme. Different types of tests were performed to study the long term material response (saturated conditions) and the transient behaviour during the initial wetting of the mixture. Both conditions are relevant for the subsequent interpretation of the real scale test.

Based on the results obtained the fundamental aspects of the hydro-mechanical response of the material were identified. Relevant findings can be summarized as follows.

Mercury intrusion porosimetry (MIP) tests were performed to characterize the multiple-porosity network of the artificially prepared packing at different dry density values ranging from 1.2 to $1.95 \mathrm{Mg} / \mathrm{m}^{3}$. The outstanding characteristic of these mixtures is its discontinuous porosity. Pore size distribution of the samples displays multi-modal pore size density functions where two main groups of pores can be identified. One group of pores corresponds to the pores inside the bentonite pellets, having sizes in the order of $10 \mathrm{~nm}$. The second group of pores is associated with the inter pellet pores (macropores) and they are four to five orders of magnitude larger. This double porosity and the highly expansive nature of the pellets controlled the hydraulic and mechanical properties of the mixture.

The saturated permeability and the swelling pressure of the material appear to be mainly controlled by the overall dry density of the sample rather than the initial grain size distribution. Results obtained are in accordance with the available data corresponding to the compacted FEBEX $\mathrm{Ca}$-bentonite. It appears that the pelletization process (pre heating and compression) is not affecting the longterm response of the material.

The hydraulic response was examined by means of infiltration tests where the evolution of the saturated permeability was investigated. Material response during a fast hydration process can be described assuming two different phases. During the initial phase water goes into the sample through the interconnected macroporosity and the bentonite pellets remain almost unchanged. During this stage, very high inflow rates are computed in correspondence with high permeability values. After this initial phase, the bentonite pellets start to hydrate exchanging water with the water stored in the macropores. The bentonite granules swell filling the macropores and reducing dramatically the permeability four orders of magnitude. Modelling the hydraulic response of the material, will require consideration of the evolution of the material structure as the hydration progresses.

The volume change response was investigated by means of suction controlled oedometer tests performed using oedometers. Loading at constant suction, wetting under constant load and wetting at constant volume tests were performed to examine the material compressibility and its swelling response as the hydration progresses (suction decreases). The observed behaviour was interpreted considering the fundamental ideas presented by Alonso et al. (1990) in the Barcelona Basic Model (BBM). The model was used to reproduce the two fundamental mechanisms of volume change observed in the material, one associated with the swelling of the bentonite granules and the other with the granular packing response.

During hydration, the material is subjected to important fabric changes induced by wetting and loading. The evolution of the intergranular forces holding the global structure stable and the change of pellet stiffness explain the volume changes induced by loading and the overall structural collapses observed during fast flooding events of low density mixtures.

These aspects of the material response were discussed by means of the elastic and elastoplastic compressibility changes and through the shape and position of the loadcollapse (LC) yield surface of the model. Parameter values associated with the elastic and elastoplastic compressibility and the overconsolidation stress were derived from the loading at constant suction and swelling pressure tests per- 
formed. It is concluded that the BBM offers a convenient conceptual framework to describe this pellet based material compacted at the dry density expected "in situ" in the EB test.

\section{Acknowledgements}

The work described has been supported by ENRESA through the 'Engineered barrier emplacement experiment in Opalinus clay (EB experiment)' (2000-2003). The authors also acknowledge the financial support provided by the EC under the contract FIKW-CT-2000-00017.

\section{References}

AITEMIN, 2001. The EB experiment engineered barrier emplacement in Opalinus Clay. Test Plan, version 3.0. NAGRA, Switzerland.

Alonso, E.E., Hoffmann, C., 2005. Modelling the field behaviour of a granular expansive barrier. In: 2nd International Meeting on Clays and Natural and Engineered Barriers for Radioactive Waste Confinement, Tours, France.

Alonso, E.E., Gens, A., Josa, A., 1990. A constitutive model for partially saturated soils. Géotechnique 40 (3), 405-430.

Cuisinier, O., 2002. Comportement hydromé-chanique des sols gonflants comactés. PhD Thesis. Institut National Polytechnique de Lorraine.
Di Mariano, A., Airò Farulla, C., Valore, C., 2000. Retention curves and 1-D behaviour of a compacted tectonised unsaturated clay. In: Tarantino, A., Mancuso, C. (Eds.), Experimental Evidence and Theoretical Approaches in Unsaturated Soils, Proc. Int. Workshop on Unsaturated Soils, Trento, Italy. Balkema, Rotterdam, pp. 47-64.

ENRESA, 2000. FEBEX project. Full-scale engineered barriers experiment for a deep geological repository for high level radioactive waste in crystalline host rock. Final report. ENRESA, Madrid.

Hoffmann, C., Romero, E., Alonso, E.E., 2005. Combining different controlled-suction techniques to study expansive clays. In: Tarantino, A., Romero, E., Cui, Y.J. (Eds.), Advanced Experimental Unsaturated Soil Mechanics, Proc. Int. Symposium on Advanced Experimental Unsaturated Soil Mechanics, Trento, Italy, 27-29 June 2005. Taylor \& Francis Group, London, pp. 61-67.

NAGRA, 2003. Engineer barrier emplacement experiment in Opalinus Clay (EB). Granular Material Emplacement QA Report with Emplacement Description. Deliverable D12 of the EB Project.

Pusch, R., Bluemling, P., Johnson, L., 2003. Performance of strongly compacted MX-80 pellets under repository-like conditions. Applied Clay Science 23, 239-244.

Romero, E., 2001 Controlled-suction techniques. $4^{\circ}$ Simpósio Brasileiro de Solos Nâo Saturados. In: Gehling, W.Y.Y., Schnaid, F. (Eds.), Porto Alegre, Brasil, pp. 535-542.

Yahia-Aïsa, M., Delage, P., Cui, Y.J., 2001. Suction-water content relationship in swelling clays. In: Clay Science for Engineering: Proceedings of the International Symposium on Suction, Swelling, Permeability and Structure of Clays. Balkema, Rotterdam. 